Meta

Journal des tradlucteurs

Translators' Journal

\title{
La traduction au pays des Tsars et des Soviets
}

\section{Henri Van Hoof}

Volume 35, numéro 2, juin 1990

URI : https://id.erudit.org/iderudit/004548ar

DOI : https://doi.org/10.7202/004548ar

Aller au sommaire du numéro

Éditeur(s)

Les Presses de l'Université de Montréal

ISSN

0026-0452 (imprimé)

1492-1421 (numérique)

Découvrir la revue

Citer cet article

Van Hoof, H. (1990). La traduction au pays des Tsars et des Soviets. Meta, 35(2),

277-302. https://doi.org/10.7202/004548ar d'utilisation que vous pouvez consulter en ligne.

https://apropos.erudit.org/fr/usagers/politique-dutilisation/ 


\section{LA TRADUCTION AU PAYS DES TSARS ET DES SOVIETS}

HENRI VAN HOOF

Waterloo, Belgique

\section{AVANT L'AVĖNEMENT DU RUSSE}

Quand, en 864, l'évêque Cyrille et son frère Méthode, moine dans un monastère de l'Olympe, répondant à l'injonction de l'empereur byzantin Michel III (842-867), quittèrent leur Macédoine natale pour entreprendre la conversion des peuplades slaves établies de la Dalmatie à la Pologne, ils ne se doutaient certainement pas que leur action allait déclencher un processus dont l'aboutissement ne serait rien de moins que l'enfantement de la langue russe. Cyrille (827-869) et Méthode (825-885), originaires de la région de Salonique, avaient pour langue maternelle le slavon ou vieux-slave (ou vieux-bulgare), qui reposait sur un parler de la Macédoine méridionale. C'est le plus ancien des dialectes slaves connus, mais jusqu'à l'époque des deux évangélisateurs il n'était pas écrit. Or, pour s'embarquer dans leur mission, Cyrille et Méthode se voulurent armés de la parole divine et décidèrent de traduire le Nouveau Testament, le Psautier, le Sacramantaire et certains autres textes sacrés du grec en slavon. Leur première tâche fut de trouver un système qui leur permît de noter les sons de la langue parlée. C'est ainsi qu'ils créèrent l'alphabet glagolitique (de glagol = parole en slavon), basé sur la minuscule grecque stylisée et complété par quelques signes d'origine orientale. Réformé par des disciples inconnus des apôtres de la Moravie, il fut remplacé par l'alphabet cyrillique, qui est tiré de la capitale grecque et qui fut bientôt le seul à subsister, celui dont allait se servir la langue russe. Mais si la traduction en slavon a, dès le IX $\mathrm{X}^{\mathrm{e}}$ siècle, acquis ses lettres de noblesse grâce à l'œuvre de Cyrille et de Méthode, les premières traductions en vieuxrusse ne feront leur apparition que deux siècles plus tard.

Cependant, aux confins sud des territoires qui font à présent partie de l'Union soviétique, la Géorgie et l'Arménie connaissaient déjà une prodigieuse activité traduisante. Il est vrai que ces deux nations, charnières entre l'Orient et l'Occident, terres d'invasion par les Grecs, les Romains, les Perses et les Arabes, mais aussi creusets de cultures, s'étaient dotées très tôt d'un alphabet et d'une langue propres.

La Géorgie, christianisée dès le III ${ }^{e}$ siècle, possédait déjà sa première traduction de la Bible deux siècles plus tard. Non seulement la vie spirituelle, mais la vie intellectuelle et littéraire tout entière se trouvait aux mains de l'Église. $\mathrm{Au} \mathrm{IX}{ }^{\mathrm{e}}$ siècle, le moine Grégoire de Khanztha fit construire le monastère de Chatberdi, qui devint le berceau de la littérature géorgienne où furent traduites du grec toutes les œuvres philosophiques et religieuses. C'est d'Opisa, le principal centre de ces traductions, que sortit en 913 la célèbre copie de I'Évangile. À Ichkhani, à Khakhouli, à Parkhali, etc., d'autres cloîtres installèrent des écoles de traduction et développèrent même une méthode propre. $\mathrm{Au} \mathrm{X}^{\mathrm{e}}$ siècle encore, la Sagesse de Balavar, recueil de légendes orientales sur la vie de Bouddha composé par un écrivain géorgien, fut traduit en grec par le moine Euthyme de Mthatsminda et, par la suite, en latin. Devenus trop nombreux dans leur pays, les moines géorgiens essaimèrent et fondèrent des monastères au Mont Athos, au Mont Sinaï, en Palestine, en Syrie. Tous devinrent des foyers de la culture géorgienne. Au couvent du Mont Athos, sous l'égide de Georges de Mthatsminda, quatre-vingts jeunes moines érudits 
consacrèrent leur vie à traduire du grec plus de deux cents livres saints. Georges luimême fut l'un des savants et des traducteurs les plus distingués de son temps. Versé dans la langue grecque, il termina la traduction de nombreux manuscrits commencée par ses prédécesseurs et s'attacha surtout à la traduction des Évangiles. Les textes sacrés traduits par lui sont ceux qu'a conservés l'Église géorgienne jusqu'à nos jours, dans la langue du $\mathrm{XI}^{\mathrm{e}}$ siècle qui était celle du traducteur. Vers 1091, le monastère géorgien du Monténégro voyait travailler soixante moines sous l'autorité d'Ephrem Mtziré, philosophe, historien et traducteur, auteur de plus de soixante-dix œuvres originales et traductions. Un autre philosophe, Jean Pétritsi, donna vers la même époque une version géorgienne des œuvres du néo-platonicien grec Proclus. Sous le règne de David III le Constructeur (1089-1125) et de la reine Thamar (1184-1213), la Géorgie restaurée et unifiée connut une période de grand développement intellectuel et la culture géorgienne réalisait la synthèse des civilisations byzantine, grecque, arabe et persane. Les nobles parlaient l'arabe et le persan, et les auteurs arabes et persans étaient généralement lus dans le texte. La littérature persane, en particulier, devint très populaire et la plupart de ses chefs-d'œuvre furent traduits en géorgien. Le premier ouvrage profane à passer ainsi dans la langue nationale fut le roman Visramiani, librement adapté pour se conformer aux vues de la Géorgie chrétienne; suivirent rapidement l'épopée du Chah-Namé (Livre des rois) composée au $\mathrm{X}^{\mathrm{e}}$ siècle par Firdousi, le Livre de Kalila et Dimna, qui contient les fables de Pilpay recueillies en Inde à la demande du roi de Perse Khosroès, Viz et Ramin, Leila Medjnoun, Kitsai Hamsa et bien d'autres.

En Arménie, la profession de traducteur existait dans l'Église avant même la création de l'alphabet. Il ne pouvait donc s'agir que de traduction orale. Dès le début du IVe siècle, après la conversion officielle du pays au christianisme, ces interprètes (thargmanitch) avaient été chargés de transposer oralement pour les fidèles le sens de l'office divin servi en grec ou en syriaque. La traduction écrite fit son apparition tout de suite après l'invention de l'alphabet arménien (405), à l'initiative et avec la participation active des chefs spirituels, l'évêque et savant Mesrop Machtots et le patriarche Sahag Partev. Depuis le $\mathrm{VI}^{\mathrm{e}}$ siècle avant notre ère, l'Arménie vivait dans l'orbite du monde perse, et c'est pour lutter contre le mazdéisme intolérant des rois sassanides que Machtots (+ 350-441) conçut l'alphabet et traduisit la Bible (405-409) du syriaque, en collaboration avec Partev. Pendant tout le $\mathrm{V}^{\mathfrak{e}}$ siècle, appelé période des traductions classiques, la traduction n'eut pas d'autre objectif que celui de satisfaire les besoins liturgiques de l'Église et d'assurer l'éducation ecclésiastique. Après la Bible, qui reçut sa forme définitive vers 430 , les traducteurs se tournèrent donc tout naturellement vers les principales œuvres des Pères de l'Église, l'Histoire ecclésiastique et la Chronique d'Eusèbe de Césarée, les commentaires, les homélies et les canons d'Athanase d'Alexandrie, de Basile de Césarée, de Cyrille d'Alexandrie, de Cyrille de Jérusalem, d'Ephrem le Syrien, d'Eusèbe d'Emèse, d'Evagre du Pont, de Grégoire de Nazianze, de Jean Chrysostome, les apologies et réfutations d'Aristide d'Athènes, d'Épiphane de Chypre, d'Hippolyte, les sermons et épîtres d'Aphraate, d'Aytalaha d'Édesse, de Zénobe d'Amid, mais aussi des recueils hagiographiques, des œuvres d'exégétiques et toute une série de livres liturgiques. Toutes ces traductions étaient faites exclusivement à partir de deux langues, le grec et le syriaque, et la plupart des traducteurs, Machtots et Partev, bien sûr, mais aussi le théologien Eznig de Kolb (397-478), Joseph de Palen et d'autres, traduisaient indifféremment de l'une et l'autre langue. Ce qui caractérise ces traductions du $V^{\mathrm{e}}$ siècle, c'est la pureté de la langue et la distinction du style. Peut-être la qualité des traductions classiques provient-elle en partie du fait que leurs auteurs les ont réalisées à l'étranger, à l'occasion de séjours organisés à cet effet dans les centres spirituels grecs et syriaques, où non seulement les riches bibliothèques leur permettaient de traduire en une fois un nombre relativement élevé 
d'œuvres sélectionnées, mais où encore ils disposaient sur place de l'aide précieuse des érudits grecs et syriens. Moïse de Khorène (407-492), qui aurait collaboré à la version arménienne de la Bible des Septante, a participé à l'un de ces voyages de traducteurs; on lui attribue aussi la traduction du Roman d'Alexandre de Pseudo-Callisthène. Pour riche et expressif qu'il fût, l'arménien de Machtots et de ses contemporains n'était toutefois pas capable de traduire directement les concepts de la science et de la philosophie grecques. $\mathrm{Ce}$ sont les traducteurs de la période hellénisante $\left(\mathrm{V}^{\mathrm{e}}\right.$-début VIII ${ }^{\mathrm{e}} \mathrm{s}$.) qui, décalquant les mots grecs correspondants, ont créé la terminologie scientifique arménienne. À cette époque, en effet, les nouvelles exigences de la société incitent les traducteurs à délaisser les écrits ecclésiastiques pour s'intéresser davantage aux réalisations de la philosophie et de la science antiques. La première traduction de l'école hellénisante fut l'Art de la grammaire de Denys de Thrace, la dernière en date, celle des œuvres philosophiques de Denys l'Aréopagite par Stéphane de Siounik. Entre les deux s'échelonnèrent des traductions des œuvres d'Aristote et de Platon, ainsi que des commentaires des philosophes néoplatoniciens Jamblicus et David L'Invincible, de l'Introduction aux Catégories d'Aristote de Porphyre de Phénicie, du Livre des connaissances utiles d'Aphtonius, des Exercices rhétoriques de Théon d'Alexandrie, des ouvrages d'anatomie de Grégoire de Nysse et de Némessie d'Emèse, des écrits théologiques d'Irénée de Lyon (Preuve de la prédication apostolique, Contre les hérésies), de Philon le Juif, etc. Il est probable que les traducteurs de l'école hellénisante, suivant en cela l'exemple de leurs prédécesseurs de la période classique, aient exécuté une partie de leurs versions à l'étranger, dans des villes comme Alexandrie, Antioche, Athènes ou Constantinople, où certains d'ailleurs avaient fait leurs études. Moins riche, la période qui va du $\mathrm{IX}^{\mathrm{e}}$ au XII $\mathrm{XI}^{\mathrm{e}}$ siècle n'en livre pas moins des traductions comme le Commentaire de l'Évangile selon saint Jean, rédigé vraisemblablement en arabe par Nonnus le Syrien, la Vie de Marouta de Maypherquat et les Actes des martyrs Bardicho et Narsay traduits du syriaque par Gaguik, prieur du monastère d'Atom, la Source de connaissance de Jean Damascène traduit du grec par Bagrat Mamikonian, le Synaxaire byzantin traduit par Joseph de Constantinople, la Géométrie d'Euclide et les dialogues Phédon et Thimée de Platon traduits du grec par Grégoire Magistros, des dizaines de Vies de saints traduites du grec et du syriaque par Grégoire Martyrophile, fils du précédent. À la fin du siècle, le prince David Curopalate commanda de traduire de l'arabe les contes La Ville d'airain et La Vierge et l'adolescent dont les sources remontent aux célèbres Mille et une nuits.

Lorsque s'achève le $\mathrm{XII}^{\mathrm{e}}$ siècle, l'Arménie et la Géorgie peuvent donc se targuer d'une tradition déjà longue en matière de traduction, alors même que la langue russe n'existait pas encore. C'est la fusion du slave ecclésiastique et de la langue populaire qui, vers le $\mathrm{XI}^{\mathrm{e}}$ siècle, donna naissance au vieux-russe, lequel à son tour engendra, dans la période qui s'étend du XII ${ }^{e}$ au XIV ${ }^{e}$ siècle, le biélorusse, l'ukrainien ou petit-russe et le russe proprement dit ou grand-russe. Mais il fallut attendre 1564 pour voir le premier livre (Actes des Apôtres) imprimé en russe et, si un premier traité grammatical parut en 1648 sous la plume de Smotritski, ce n'est qu'en 1755, l'année même de la fondation de l'université de Moscou, que la Grammaire de l'érudit Mikhail Lomonosov (1711-1765) fit vraiment la distinction entre le slavon et le russe, dont l'alphabet n'avait d'ailleurs été fixé que sous Pierre le Grand (1672-1725) et en partie par l'empereur lui-même.

Très tôt, cependant, on voit surgir des traductions où dominent les ouvrages ecclésiastiques. Les premières traductions ont été celles de livres saints: les Actes des Apôtres, les Psaumes de David, tel ou tel évangile - le plus ancien étant celui connu sous le nom d'Évangile d'Ostromir (1056-1057) dû au diacre Grigori - l'Histoire d'Alekseï, homme de Dieu et d'autres Vies de saints, mais pas même une version intégrale de la Bible, pour laquelle il fallut attendre 1499 , année qui vit paraître la traduction de Gennadi, 
archevêque de Novgorod, lequel utilisa les textes grecs et la Vulgate et se fit aider par l'abbé Josif Volocki, Dmitri Gerasimov et d'autres. Le XIII ${ }^{\mathrm{e}}$ siècle connut déjà des traductions de récits byzantins, comme le Roman d'Alexandre, l'Histoire de Troie, Barlaam et Josaphat, etc., ou de chroniques comme la Chronique de Byzance de Ioann Malalas, mais aussi de l'Histoire de la guerre judaïque de Flavius Josèphe et du célèbre Phisiologus. Au XIV ${ }^{e}$ siècle, les homélies du moine syriaque Dorofeï (?-620) furent traduites sous le titre Slova. Au XVI ${ }^{\mathrm{e}}$ siècle, le moine humaniste Michele Trivolis, dit Maxime le Grec (1475-1556) fut mandé à Moscou par le tsar Vassili pour s'atteler à la révision des textes sacrés; ses traductions, dénoncées comme non conformes à la tradition, lui attirèrent animosité et disgrâce. Vers la même époque, le prince Andreï Kourbski (1528-1583), général de son état et fervent défenseur de l'orthodoxie religieuse, apprit le latin pour traduire les Pères de l'Église, ce que fit aussi au siècle suivant le prédicateur et lexicographe Epifani Slavinecki (?-1675). Au XVII ${ }^{\mathrm{e}}$ siècle encore, le religieux et poète Simeon Petrovski-Sitnianovitch (1629-1680), appelé aussi Simeon Polotski, du nom de la ville où il fut évêque, donna une version russe des Psaumes de David et de l'Histoire de Barlaam et Josaphat, roman grec du $\mathrm{VI}^{\mathrm{e}}$ siècle basé sur une légende bouddhiste. Le jésuite Piotr Skarga traduisit du polonais les Annales ecclésiastiques de Cesar Baronius (1538-1607), qui devinrent le livre de chevet des «vieux-croyants» sous le titre abrégé Baroni. Même des textes comme la Gesta Romanorum et le Speculum magnum furent traduits à des fins religieuses, les éléments catholiques disparaissant dans les traductions. Par ailleurs, le prince moldave Dimitrie Kantemir (1673-1723), qui avait appris les langues à Constantinople et en savait quatorze dont le grec, le latin, l'arabe, le persan, le français, l'italien, etc., traduisit le Coran de l'arabe en latin et en russe. Ainsi, jusqu'au XVIII ${ }^{\mathrm{e}}$ siècle, la plupart des traductions restèrent d'inspiration religieuse, les Pères de l'Église byzantine ayant alors une influence plus grande que l'Antiquité classique ou les idées de l'Occident.

DE PIERRE LE GRAND À POUCHKINE

L'arrivée au pouvoir de Pierre le Grand (1682), qui choisit de tourner le dos à l'Orient et d'ouvrir la Russie à l'Europe, allait modifier de façon radicale non seulement le paysage social et littéraire du pays, mais aussi celui de la traduction. Dans SaintPétersbourg, qu'il fonda en 1703 et dont il fit plus tard sa capitale, il installa la première imprimerie en 1712. Pierre le Grand lui-même, dont on sait déjà la part qu'il prit à la simplification de l'alphabet, semble avoir été parmi les premiers à s'intéresser à la qualité d'une traduction si l'on en juge par ses commentaires de 1709 sur celle d'un ouvrage militaire consacré aux fortifications. Soucieux de multiplier les traductions, il dressait personnellement des listes de livres à traduire (choisis le plus souvent en fonction des impératifs pratiques de sa politique), rédigeait lui-même des instructions pour les traducteurs en insistant sur la nécessité de rendre clairement le sens du texte et d'éviter le mot à mot, contrôlait lui-même les traductions exécutées. Pour trouver les traducteurs en nombre suffisant et stimuler l'intérêt pour la traduction, l'empereur s'adressa au ministère des Affaires étrangères, aux académies ecclésiastiques de Moscou et de Kiev, à l'Académie des Sciences de Saint-Pétersbourg nouvellement créée, et alla même jusqu'à officialiser la fonction de traducteur. De nombreux littérateurs - Kondratovitch, Trediakovski, Bogdanovitch, Fonvizine, Emine, Kniajnine, etc. - débutèrent ainsi comme fonctionnairestraducteurs, élargissant ensuite leurs horizons pour approvisionner un marché qui se développait avec la multiplication des imprimeries. D'emblée, le rôle réservé au traducteur dans la Russie moderne revêtit donc une importance primordiale à la fois pour l'enrichissement de la langue russe et pour la diffusion de la pensée et de la littérature occidentales.

Dans un premier temps, ce sont l'Antiquité classique, d'un côté, les auteurs français, de l'autre, qui constituèrent les deux grands pôles de la traduction. Déjà en 1710, 
dans la première liste imprimée des livres mis en vente, figuraient des traductions anonymes d'une Histoire de la prise de Troie et de l'Histoire d'Alexandre le Grand de Quinte Curce. D'autres traductions anonymes étaient le poème Sur la guerre des grenouilles et des souris d'Homère, celle d'une partie des Métamorphoses d'Ovide et celle de l'ouvrage Des inventeurs des choses (1720) de Polidoro Virgilio d'Urbino. Mais c'est avec les traductions du prince et poète Antioch Kantemir (1709-1744), fils de Dimitrie, qu'apparurent les premiers travaux signés. Après avoir traduit du français les Satires (1727) de Boileau et les Entretiens sur la pluralité des mondes (1729) de Fontenelle avant même d'avoir atteint sa vingtième année, il révéla à la Russie les Odes (1736) d'Anacréon, ainsi que les Odes et Épîtres (1742) d'Horace traduites en vers blancs. Les traducteurs qui maniaient indifféremment le grec, le latin et le français n'étaient pas rares à l'époque. Le poète, grammairien et théoricien de la métrique russe, Vassili Trediakovski (1703-1769), l'a prouvé en traduisant du grec les Fables d'Esope en vers, du latin l'Ars Poetica et l'Épître aux Pisons d'Horace en prose, l'Eunuque de Térence en prose, du français l'Art poétique de Boileau en vers, les Aventures de Télémaque (1766) de Fénélon en hexamètres, le Voyage à l'île d'Amour de P. Tilleman, dans lequel il se repent d'avoir employé autrefois le slavon et se prononce désormais pour le russe, et surtout l'Histoire romaine de Charles Rollin et l'Histoire des empereurs romains de Jean-Baptiste Crévier, auxquelles il consacra trente années de sa vie. Son contemporain, le génial Mikhail Lomonosov (1711-1765), poète et savant qui savait le grec, le latin, le français, l'allemand et l'italien, en est une autre parfaite illustration. Sa Rhétorique (1748) contient des traductions d'Homère, d'Anacréon, de Démosthène, de Lucien, etc., pour le grec, de Virgile, d'Horace, d'Ovide, de Juvénal, de Cicéron, etc., pour le latin. Du français, il traduisit des Odes de Fénelon et de Rousseau. Le dramaturge Aleksandr Soumarokov (17181777), qui dirigea le premier théâtre public et fonda le premier journal littéraire, mit en russe des ouvres d'Horace pour le latin, de Racine et de Rousseau pour le français, de Shakespeare pour l'anglais, dont il rendit le Hamlet «en y supprimant toutes les laideurs et en n'y laissant que le beau»(!). Horace trouva encore un interprète en la personne du poète Ivan Barkhov (1732-1768), qui donna aussi de bonnes traductions de Phèdre. L'Énéide de Virgile, traduite une première fois par le poète Vassili Petrov (1736-1799), traducteur au cabinet de l'impératrice Catherine II, attira aussi le poète Nikolaï Osipov (1751-1799), auteur d'une Énéide travestie.

Catherine II (1729-1796), proclamée impératrice en 1762, était elle-même traductrice et écrivain. C'est d'ailleurs la traduction du roman idéologique Bélisaire (1768) de Marmontel, faite en collaboration, qui marqua le début de son œuvre littéraire. Elle se piqua aussi de traduire Shakespeare et Calderon, ne réussissant qu'à donner une faible version libre des Joyeuses commères de Windsor (1786) du premier et des imitations des comédies La chambre de débarras et Le Prodigue du second. Sous son règne, la rétribution des traducteurs-fonctionnaires par l'attribution d'un traitement devint la règle. Celui du poète Petrov, par exemple, était de 1200 roubles par an; celui de Trediakovski, de 660 , sans compter d'éventuelles récompenses. Car l'impératrice était généreuse pour les traducteurs qui la servaient: l'archevêque Eugène se vit octroyer 1000 roubles pour avoir traduit en grec quatre livres de l'Énéide; le poète allemand Ernst Arndt reçut une gratification très convenable pour avoir traduit en allemand des comédies de la souveraine. La plupart des fonctionnaires, cependant, devaient se livrer à des travaux de traduction supplémentaires, principalement de romans, que les nouvelles classes de lecteurs réclamaient. Pour répondre à ce besoin, s'était créée, en 1768, une Société d'Émulation pour la Traduction de Livres étrangers, qui compta 114 membres, parmi lesquels Trediakovski, Soumarokov, Radichtchev, etc. Elle œuvra pendant quatorze ans au développement de la traduction littéraire et provoqua de nombreuses discussions sur des problèmes théoriques. 
La traduction des poèmes homériques, en particulier, passionna les lettrés russes

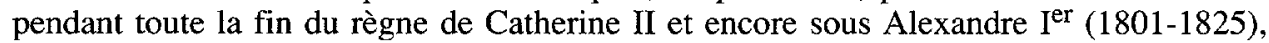
parce qu'elle touchait au sort même du vers russe: hexamètre de type grec ou alexandrin de type français? Le poète Ermil Kostrov (1750-1796), qui avait traduit en 1786 les six premiers chants de l'lliade en vers ïambiques, se fit attaquer par Radichtchev pour n'avoir pas utilisé l'hexamètre «plus proche du grec». Ce qui n'empêcha pas le poète et dramaturge Vassili Kapnist (1757-1823) de traduire l'Iliade et l'Odyssée en alexandrins, sur le modèle des traductions françaises. Il est d'ailleurs probable qu'il se servit d'une version française intermédiaire comme il le fit pour sa nouvelle version des Odes d'Horace, car dans sa polémique avec Gneditch il avoue que «ne connaissant pas le grec il ne pouvait juger du degré d'agrément du vers homérique pour les Grecs»(!). Or, Nikolaï Gneditch (1784-1833), poète mais aussi helléniste, après avoir traduit six chants de l'Iliade en alexandrins lui aussi, s'était aperçu qu'il faisait fausse route et, reprenant le travail à zéro, traduisit l'œuvre tout entière en hexamètres. Terminée en 1829 après un labeur de vingt années, elle demeure une réussite de qualité poétique et de fidélité. Gneditch fut incontestablement un grand serviteur des Anciens car, l'Iliade mise à part, il traduisit encore les Hymnes d'Homère, les Idylles de Théocrite, des Chants populaires de la Grèce contemporaine. D'une activité aussi variée que débordante, il s'intéressa en outre aux langues modernes et traduisit notamment la Conjuration de Fiesque à Gênes de Schiller, des cuvres de Byron et de Shakespeare, les meilleurs morceaux de Voltaire et de Chénier. Ses traductions de Shakespeare ont été faites sur des versions françaises, comme il arrivait souvent à l'époque dans le cas d'auteurs anglais.

Le français, en effet, était alors la langue moderne la plus en vogue, les livres français suscitaient l'engouement le plus grand, les auteurs français étaient avec les Anciens les plus traduits. La réputation des auteurs, le genre littéraire ne pesaient guère dans les choix. Trediakovski déjà, dans le contrat qui le liait avec l'Académie des Sciences, s'engageait à «traduire du français en russe tout ce qui lui est donné». Le même manque de discernement caractérise ses successeurs. L'auteur dramatique Vladimir Loukine (1737-1794) n'a écrit qu'une seule comédie originale mais a, en revanche, traduit ou adapté diverses pièces comme Le Bijoutier de Philippe Destouches, L'Amante amant de Jean de Campistron, etc. Mikhaill Popov (1742-1790), poète et auteur dramatique lui aussi, mit en russe la comédie Deucalion et Pyrrha (1765) de Germain Poulain de SainteFoix. Aleksandr Radichtchev (1749-1802), l'adversaire de Kostrov dans la querelle de la métrique homérique, traduisit les Réflexions sur l'histoire grecque (1773) du philosophe et historien Gabriel Bonnot de Mably. Le poète Ippolit Bogdanovitch (1743-1802), qui entra en 1763 comme traducteur au ministère de la Guerre, parvint à la célébrité par son excellente traduction-paraphrase du roman Les Amours de Psyché et de Cupidon de La Fontaine, qu'il publia sous le titre Douchenka (1775); elle contribua à l'introduction du style classique français dans la littérature russe. La princesse Ekaterina Dachkova (17431810), qui fut présidente de l'Académie russe, traduisit l'Essai sur la poésie épique de Voltaire. Le fabuliste Ivan Khemnitzer (1745-1784) mit en russe une cinquantaine de Fables de La Fontaine, ces mêmes fables que le grand Ivan Krylov (1768-1844) allait traduire à son tour pour découvrir sa vocation de fabuliste. L'écrivain satirique Denis Fonvizine (1745-1792), qui débuta comme traducteur-fonctionnaire également, s'attacha à rendre des œuvres aussi disparates que le roman philosophique Séthos. Histoire ou vie tirée des monuments et anecdotes de l'Ancienne Égypte de l'abbé Jean Terrasson, la tragédie anticléricale Alzire de Voltaire, le drame moral Sydney de Jean-Baptiste Gresset. Le poète-soldat Denis Davidov (1784-1801) traduisit La Rivière et le miroir de Louis-Philippe De Ségur. Vladislav Ozerov (1769-1816), qui aborda la poésie par des vers français, fut aussi l'auteur d'une traduction des Lettres d'Héloise à Abélard (1810) et d'imitations de 
Racine. Le professeur Strakhov, qui vécut sous Alexandre $\mathrm{I}^{\mathrm{er}}$, traduisit le Voyage du jeune Anacharsis en Grèce de l'abbé Jean-Jacques Barthélémy, pour lequel le souverain le gratifia de 6000 roubles. Alexandre $\mathrm{I}^{\mathrm{er}} \mathrm{n}$ 'apparaît donc pas moins libéral que Catherine II, et les 5000 roubles qu'il remit à Politkovski pour ses traductions du philosophe anglais Adam Smith en sont une preuve supplémentaire. Une preuve aussi que l'on traduisait autre chose que du français, autre chose que des œuvres littéraires.

Même si les traductions de l'anglais, de l'allemand ou d'autres langues européennes ne peuvent rivaliser en nombre avec celles du français, elles n'en sont pas moins une vivante illustration de la multiplicité des centres d'intérêt de la société russe de l'époque. De l'anglais, Petrov - connu déjà comme interprète de Virgile - traduisit le Paradise Lost de John Milton et des œuvres d'Alexander Pope. Kapnist, le traducteur homérique, fut aussi celui qui révéla au public russe les Poèmes d'Ossian de James Macpherson, dont Kostrov - autre traducteur d'Homère - donna une nouvelle version. Fielding, Goldsmith, Sterne, Richardson furent parmi les plus traduits, en particulier le dernier nommé avec ses romans Sir Charles Grandison, Clarissa Harlowe et Pamela. De l'allemand, Soumarokov traduisit des poésies de Paul Fleming. Khemnitzer, qui s'était déjà intéressé à La Fontaine, traduisit aussi des fables de Christian Gellert, tandis que Fonvizine gagnait ses premiers honoraires - l'équivalent de cinquante roubles en livres étrangers! - en traduisant les Fables de Goldberg alors qu'il était encore étudiant ; par la suite, il produisit encore une traduction du roman Karita et Polidor, ainsi que des pièces du dramaturge danois Ludwig Holberg sur des versions intermédiaires allemandes. Le poète et auteur dramatique Gavril Derjavine (1743-1816) mit en russe des pièces de Friedrich Klopstock et un autre dramaturge allemand, August Kotzebue, passe pour avoir fait la fortune du traducteur Krasnapolski, qui s'était fait l'interprète attitré de cet auteur prolifique et très en vogue. Parmi les autres poètes traduits, il y a le Suisse Albert Haller avec son poème L'Éternité, l'Allemand Barthold Brockes avec son recueil Irdisches Vergnügen in Gott, etc. Dans le domaine des sciences, Lomonosov fit paraître une traduction de la Physique expérimentale du mathématicien Christian von Wolff, avec lequel il s'était lié d'amitié en Allemagne. De l'italien, Fedor Volkov (1729-1763), fondateur du premier théâtre de Saint-Pétersbourg et également traducteur de l'allemand et du français, traduisit La Clemenze de Tito de Pietro Trapassi, dit Metastasio.

II reste que les traducteurs du XVIII ${ }^{\mathrm{e}}$ siècle ont été avant tout les défricheurs de l'Antiquité gréco-latine et du domaine français. Ces représentants de l'école classique ou pseudo-classique étaient encore influencés dans leur écriture par la doctrine des trois styles formulés par Lomonosov, qui codifiait étroitement l'emploi des vocabulaires selon les genres littéraires. Si leur écriture demeure encombrée de slavonismes, si elle accuse un caractère quelque peu livresque, on ne peut toutefois nier l'immense service qu'ils ont rendu à la langue russe en contribuant à l'élaboration de nouveaux moyens d'expression.

Avec Nikolaï Karamzine (1766-1826), dont la personnalité domina la scène littéraire de la fin du règne de Catherine II et le début du XIX ${ }^{\mathrm{e}}$ siècle, qui annonçait déjà le romantisme, deux tournants s'amorcèrent: celui de la modernisation de la langue russe, d'une part, celui de l'ouverture aux domaines anglais et allemand, d'autre part. Écrivain, éditeur-journaliste, historien, Karamzine introduisit un style nouveau qui rompait avec la règle de Lomonosov, limitant l'emploi des slavonismes, incorporant de nombreux néologismes, harmonisant les rapports entre slavon et russe, bref créant le russe littéraire moderne que le génie de son ami Pouchkine fixera peu de temps après. Traducteur infatigable, il le fut pour alimenter sa revue Le Courrier de l'Europe, semblable en cela à d'autres journalistes comme avant lui Fedor Emine (1735-1770), traducteur de romans d'aventures, journalistes qui étaient souvent les principaux traducteurs de leur organe. Par sa première traduction, Karamzine annonçait déjà sa prédilection : il s'agissait du Dialogue 
de Marie-Thérèse d'Autriche avec notre impératrice Élisabeth aux Champs-Élysées, traduit de l'allemand, pour lequel il reçut en paiement les deux volumes du Tom Jones de Fielding. Car s'il produisit aussi des traductions de Démosthène, de Cicéron, de Salluste pour les Anciens, des Contes de Marmontel et d'œuvres de Madame de Staël pour le français, ce sont surtout des auteurs allemands comme Lessing et Gessner, ou anglais comme Shakespeare, Macpherson (Ossian), Sterne et James Thomson - dont il traduisit Les Saisons - qu'il voulut mettre à la portée de ses contemporains.

\section{DE POUCHKINE À LA RÉVOLUTION}

Tout de suite après Karamzine commence la période pouchkinienne, l'âge d'or de la traduction en Russie: près de six cents traductions entre 1801 et 1805 , parmi lesquelles 176 romans, dont 115 du français, 51 de l'allemand, 4 seulement de l'anglais. Mais si elles sont encore, au début, négligées au profit de la française, les littératures allemande et anglaise allaient trouver bientôt des interprètes dignes d'elles, qui feraient de leurs chefs-d'œuvre des chefs-d'œuvre du patrimoine littéraire russe.

L'attrait pour les Anciens n'avait pourtant rien perdu de sa force. Le critique Alekseï Merzljakov (1778-1830) se montra très prolifique en traduisant du grec des œuvres de Pindare, d'Euripide, d'Eschyle, de Théocrite, d'Homère, de Sappho, de Callimaque, de Bion, de Sophocle, tandis que du latin il traduisait Virgile, Horace, Tibulle, Properce, Ovide. Le grand poète romantique Vassili Joukovski (1783-1852), qui révélera plus tard les romantiques allemands et anglais, débuta dans la traduction avec une Ode de Sappho et, après avoir donné aussi deux chants de l'Iliade et des fragments de la Batrachomyomachie d'Homère, ainsi que l'épisode de la Chute de Troie dans l'Énéide de Virgile, termina sa carrière par une version très contestée de l'Odyssée (1847) pour laquelle l'helléniste Grasshof dut lui préparer une transcription mot à mot en allemand, car il n'entendait pas le grec. Le poète Konstantin Batiouchkov (1787-1855) traduisit du latin classique des pièces de Tibulle, mais aussi du latin moderne des œuvres de Pétrarque. Même le grand Aleksandr Pouchkine (1799-1837), pour qui les traducteurs étaient «les chevaux de poste de l'instruction», transposa assez librement du grec - à partir de versions françaises - des poèmes d'Anacréon et d'Ion de Chios et, du latin, une Ode d'Horace et des ouvres de Catulle et de Juvénal. La jeune poétesse Elisaveta Kulmann (1808-1825), qui connaissait onze langues à quinze ans et composait en russe, en français et en allemand, traduisit du grec des Odes d'Anacréon et de Pindare et, du latin, des Odes d'Horace. Le poète Vadim Cherchénévitch, inventeur de l'imagisme, publia une nouvelle version de l'Énéide (1854). Le poète et critique Apollon Grigorev (1822-1864) traduisit des œuvres de Sophocle. Le poète Mikhail Mikhailov (1829-1865) se fit l'interprète de toute une série d'auteurs grecs: Eschyle, Sappho, Anacréon, Moschos, Simonide. Cet intérêt pour le monde gréco-latin devait d'ailleurs se maintenir tout au long du siècle puisque, sur la fin, le poète Innokenti Annenski (1856-1909) donnait encore des traductions d'Euripide et d'Horace, le poète Afanasi Fet (1820-1892) de son vrai nom Chenchine - traduisait les Euvres complètes (1884) du même Horace, et l'érudit Basile Latichev (1855-1921) — qui collabora aux travaux de l'école française d'Athènes - publiait sous le titre Scythica et Caucasica la traduction de textes antiques relatifs à son pays.

Le français non plus n'avait rien perdu de son emprise sur les milieux cultivés. Il était pratiqué couramment dans les salons, au point que Gneditch pouvait, en 1812 encore, reprocher à ses compatriotes de ne point parler le russe entre eux. Il était donc normal que les traductions du français continuent de foisonner. Joukovski traduisit Mérimée. Batiouchkov fit paraître dans le Courrier de l'Europe des traductions de poèmes d'Évariste de Forges, comte de Parny. Des deux mêmes auteurs, Pouchkine traduisit 
respectivement La Guzla ou Choix de poésies illyriques et Les Déguisements de Vénus, outre des poèmes de Marot, de Voltaire et d'André Chénier. Mérimée trouva encore des interprètes dans le nouvelliste Vsevolod Garchine (1855-1888) et dans le romancier Dmitri Grigorovitch (1822-1900), dont la mère était une émigrée française. Grigorev russifia les Chansons de Béranger. Le poète comique Nikolaï Khmelnitski (1789-1846) débuta par des traductions du Tartufe et de l'École des femmes de Molière, dont d'autres comédies encore seront traduites plus tard par l'écrivain révolutionnaire Dimitri Minaev (1835-1889) et par le savant et littérateur Semen Vengerov (1855-1921). Le critique dramatique Sergeï Eksakov (1791-1859) embrassa les lettres en traduisant la tragédie Philactète (1816) de Jean-François La Harpe. L'ami de Pouchkine, Piotr Viazemski (1792-1878), prince et poète, publia une traduction assez décevante du roman Adolphe (1830) de Benjamin Constant. Les plus grands noms de la littérature russe n'hésitaient pas à se lancer dans l'aventure de la traduction: Ivan Tourguenev (1818-1883) traduisit deux nouvelles de Flaubert; la première œuvre publiée de Fedor Dostö̈evski (1821-1881) fut une traduction du roman Eugénie Grandet de Balzac; Léon Tolstoï (1828-1910) mit en russe des nouvelles de Guy de Maupassant. Mais, à leurs côtés, une cohorte de traducteurs brillants leur donnaient la réplique. Le philosophe et publiciste Nikolaï Mikhaïlovski (1842-1904) fit ses débuts en littérature par une traduction de La Démocratie de Proudhon. Le poète Piotr Veinberg (1830-1908) fut parmi les premiers à traduire Victor Hugo, avec le critique Viktor Bourenine qui fut aussi un interprète des poèmes d'Alfred de Vigny, et avec le satiriste Vassili Kourotchkine (1831-1875) qui traduisit aussi des œuvres de Barbey d'Aurevilly ainsi que les poèmes Les Fous, Les infiniment petits, Les Nègres et les marionnettes, Nabuchodonosor et Le Marquis de Carabas de Béranger. Les Fleurs du mal de Beaudelaire furent traduites pour la première fois par Peter Jakoubovitch (1860-1911), mais des poèmes du même auteur parurent aussi dans des versions du poète et critique Sergeï Andreevski (1847-1920), qui traduisit aussi Musset, et du poète Annenski, lequel se fit encore l'interprète de Rimbaud, de Verlaine, de Mallarmé. Dans le domaine non littéraire, le philosophe Sergeï Troubetzkoï (1862-1905) traduisit Les Religions de l'Inde peu de temps après leur publication en 1879 par l'indianiste Auguste Barth. Cette dernière traduction, celles de Hugo et des symbolistes montrent que les traducteurs russes se rapprochaient petit à petit de leur temps pour suivre l'actualité de plus en plus près.

C'est le romantisme qui allait permettre aux littératures allemande et anglaise de concurrencer la française. C'est son chef de file, Joukovski, qui fut le grand révélateur des romantiques allemands et anglais, dont il russifia les œuvres avec une maîtrise telle que ses traductions égalèrent en renommée les originaux. Ce n'est pas sans raison qu'il a été surnommé le «créateur de l'école de traduction russe». À ses débuts - il avait dixhuit ans - Joukovski avait traduit d'August Kotzebue les quatre volumes de Die jüngsten Kinder meiner Laune (1801), pour lesquels il fut payé soixante-quinze roubles. C'est après seulement qu'il mit son talent au service des Bürger, Schiller, Goethe, Klopstock, Uhland, Hebbel et d'autres. De Friedrich Schiller, il traduisit notamment Die Jungfrau von Orleans; de Gottfried Bürger, il interpréta la ballade Lenore de trois façons différentes, d'abord dans les adaptations Ludmilla (1808) et Svetlana (1812), puis sous la forme d'une traduction fidèle, Lenore (1831); de Friedrich de la Motte Fouqué, il russifia le conte de fées Undine (1837), etc. Le poète Pavel Katenine (1792-1833) se livra à un exercice similaire sur une ballade de Bürger en en publiant deux traductions sous les titres respectifs de Natacha et Olga. Goethe, Schiller, Heine sont les auteurs qui tentèrent le plus grand nombre de traducteurs. Tous trois furent traduits par le poète et diplomate Fedor Tioutchev (1803-1873), qui fut en poste en Allemagne; par le poète et romancier Mikhail Lermontov (1814-1841), parfait connaisseur de la langue allemande dans laquelle 
il écrivit sa tragédie Menschen und Leidenschaften, qui donna de ses modèles des traductions d'une admirable liberté; par le poète et dramaturge Lev Meï (1822-1862), excellent linguiste qui savait l'hébreu, le grec, le latin, l'anglais, l'allemand, le français, l'italien; par Grigorev, qui se fit en plus l'interprète de Herder; par Mikhaïlov, qui publia aussi des traductions de Uhland. Goethe et Schiller trouvèrent encore un interprète en la personne de l'écrivain et critique Konstantin Aksakov (1817-1860), Goethe et Heine en celles du poète Apolon Maikov (1821-1897) et de Minaev. Goethe, lui, fut encore traduit par l'auteur dramatique Aleksandr Griboedov (1793-1829), diplomate, lettré et linguiste qui savait l'allemand, le français, l'anglais, l'italien, le grec, le latin, l'arabe et le persan, ainsi que par le poète Eduard Gruber (1814-1847), auteur d'une excellente version du Faust; par Fet qui, à côté d'une nouvelle version de Faust, traduisit aussi le poème Hermann und Dorothea; par Nikolaï Gerbel (1827-1883), qui par ailleurs publia des traductions de Hoffmann et une anthologie de poètes allemands. Schiller, pour sa part, fut encore traduit par Vengerov et par Veinberg, ce dernier transposant aussi des ceuvres de Lessing et de Herwegh. Heine, enfin, fut encore traduit par Bourenine, par Fet et par le poète Alekseï Plechtcheev (1825-1893), qui débuta en littérature par des poésies traduites de Friedrich Ruickert. En dehors du champ littéraire, il convient de noter une traduction magistrale de l'ouvrage Asien (1856-1860), du géographe Karl Ritter, due au voyageur et géographe Piotr Semionov (1827-1914) en collaboration avec Grigorev et Khanikov; une traduction de l'Histoire universelle de l'historien Georg Weber par le philosophe et savant Nikolaï Tchernichevski (1828-1889); les traductions du philosophe Arthur Schopenhauer par Fet; une traduction du Manifeste communiste (1882) par l'écrivain et homme politique Gheorghi Plekhanov (1856-1928), premier propagandiste marxiste en Russie, qui traduisit aussi de nombreux autres écrits de Karl Marx et de Friedrich Engels, de même que l'économiste et philosophe Vladimir Bazorov (1874-), affilié au mouvement ouvrier révolutionnaire dès 1896 , qui traduisit Das Kapital avec I. Stepanov.

La plupart des traducteurs de l'allemand abordèrent également le domaine anglais. À commencer par Joukovski lui-même, qui traduisit une Elegy de Thomas Gray dès 1802, mais aussi des poésies de Thomas Moore, Robert Southey, Walter Scott, Thomas Percy, James Thomson, Thomas Campbell et, bien sûr, George Byron, dont il donna le Prisonnier de Chillon. Byron, vivant modèle du romantisme, fut l'auteur le plus prisé par les traducteurs de l'époque, ne trouvant de rival qu'en Shakespeare. L'un et l'autre furent traduits par Pouchkine, qui produisit notamment des imitations libres de Mesure pour mesure et du Marchand de Venise et se fit encore l'interprète d'auteurs aussi divers que Samuel Coleridge, Barry Cornwall, John Wilson (L'Orgie pendant la peste) et d'autres; par Gerbel, qui publia une traduction des œuvres complètes de deux auteurs, ainsi qu'une anthologie de poètes anglais; par le romancier et journaliste Grigori Danilevski (1829. 1890); par Veinberg, qui traduisit en outre Shelley et Sheridan; par Vengerov aussi. Byron trouva encore des interprètes en Kozlov, le poète aveugle, qui russifia la Fiancée d'Abydos et qui, malgré le culte qu'il vouait à son modèle, traduisit aussi des poèmes de Thomas Moore; par Minaev, qui traduisit également Moore et Burns; par Tioutchev, par Grigorev, par Mikhaïlov, ce dernier publiant en outre des traductions de poésies de Spenser et de Longfellow. Quant à Shakespeare, sa tragédie Hamlet connut sa première véritable traduction, en lieu et place des adaptations dont elle avait dû se contenter jusque-là, en 1838; elle était due à l'écrivain, journaliste et historien Nikolaï Polevoï (1796-1846). C'est dans le même esprit que Fet se voua, lui aussi, à la traduction de l'œuvre shakespearienne. Des auteurs comme Dickens et Thackeray se virent russifiés par Vvedenski, tandis que les poèmes d'Edgar Poe étaient traduits pour la première fois par Andreevski. Dans le domaine non littéraire, Tchernichevski traduisit les Principes d'économie politique de Stuart Mill. 
En regard de cette abondance, les traductions des langues latines font figure de parent pauvre. Il y a bien la précoce Elisaveta Kulmann qui traduisit du portugais des poèmes de Manoël. Il y a l'infatigable Joukovski qui se hasarda à traduire de l'espagnol des fragments de Cervantès. Il y a aussi son jeune ami Pouchkine qui traduisit de l'italien des morceaux de l'Arioste et d'Alfieri. Il y a Veinberg, qui se fit l'interprète de Dante, tout comme Minaev qui publia une version de la Divina Commedia ainsi que des poésies de Leopardi. Mais l'explorateur le plus actif du domaine italien fut sans doute le poète Kozlov qui, avant même le milieu du siècle, avait mis en russe des œuvres de Pétrarque, quelques épisodes de la Gerusalemma liberata du Tasse et des fragments de l'Orlando furioso de l'Arioste, Ermengarde mourante de la tragédie Adelchi de Manzoni, des fragments de Giovanni da Procida de Niccolini, la ballade Fiorina de Tommaso Grossi, etc.

Pour la première fois apparurent des traductions du polonais. Toutes, faut-il s'en étonner, se rapportaient à l'œuvre du romantique Adam Mickiewicz. Elles étaient de la main de son ami Pouchkine, mais aussi de Kozlov et de Veinberg. Il y eut aussi les premières incursions dans des terres plus exotiques. Joukovski, toujours lui, traduisit du sanskrit des épisodes de la Mahâbhârata et, du persan, des fragments de Rouston et Zorab du poète épique Firdousi, le tout vraisemblablement sur des versions allemandes antérieures. Le sinologue et académicien $\mathrm{V}$. Vasiliev mit en russe plusieurs extraits du Che-King (Livre des vers), classique de la dynastie Tchéou. Le romancier Nikolaï Garine (1852-1906), tard venu à la littérature après avoir parcouru le monde en passant par la Sibérie, la Corée, la Chine, la Japon, Hawaii et New York, traduisit du coréen soixantequatre contes du folklore local.

Parallèlement se produisait un phénomène de retour aux sources tout à fait remarquable. La langue russe, assouplie et enrichie par les réformes de Karamzine, pétrie par le travail des traducteurs, mûrie par l'essor de la littérature nationale, s'était à ce point transformée que d'aucuns estimèrent nécessaire de traduire en russe moderne les textes les plus anciens. C'est ce que firent Joukovski, Pouchkine, Gerbel, Maïkov, Minaev, Meï et d'autres pour le Dit de la campagne d'Igor, principal poème épique de la littérature du XII ${ }^{\mathrm{e}}$ siècle. Une autre tendance qui se dessinait, c'est l'intérêt pour les littératures des divers peuples de l'Empire russe. Tourguenev lui-même montra l'exemple en traduisant de l'ukrainien le premier volume des Nouvelles de sa contemporaine Marja Marko-Vovtchok.

L'intense activité de traduction qui façonna tout le XIX ${ }^{\mathrm{e}}$ siècle, activité à laquelle s'adonnèrent les plus grands noms de la littérature en pleine expansion, ne pouvait manquer de provoquer des discussions sur la manière de traduire. Alors qu'il était admis que des traductions fussent faites à partir de versions intermédiaires, essentiellement françaises et allemandes, méthode adoptée encore même par Pouchkine et Joukovski, les polémiques nées autour de la traduction des Anciens firent apparaître que, quels que fussent les dons de poète du traducteur, il lui était indispensable d'avoir une connaissance directe de la langue originale. À la question de savoir s'il faut traduire la poésie en vers ou en prose, Joukovski avait répondu que «le traducteur d'un poète est lui-même un créateur; le traducteur en prose est un esclave, le traducteur en vers un rival». Traduire était donc perçu comme un acte esthétique, et c'est là peut-être ce qui explique qu'en Russie, même de nos jours, la traduction littéraire porte le nom de traduction artistique. Cette conception de l'art pour l'art fut reprise par Fet, qui devint le chef de file de la traduction dite aristocratique et de la littéralité (dans le bon sens du terme, en réaction à l'adaptation), procédé qu'il applique lui-même à ses traductions de Shakespeare. À cette tendance appartenaient aussi Maikov et d'autres. À l'opposé se situait l'école de la traduction dite démocratique, avec des représentants comme Plechtcheev, Mikhailov, Kourotchkine, Minaev, etc. Mais ces querelles d'écoles ne donnèrent jamais lieu à des écrits théoriques formels. Il faudra pour cela attendre la période révolutionnaire. 


\begin{abstract}
L'ĖRE SOVIÉTIQUE
L'ère soviétique pourrait s'appeler l'ère de la traduction organisée. L'État soviétique issu de la Révolution de 1917 est un État multinational, qui regroupe plus de cent peuples dont la constitution garantit les langues individuelles. Comme Staline lui-même le proclamait déjà en 1925, la culture devait être «socialiste par le contenu, nationale par la forme». La diffusion de l'idéologie nouvelle dans différents territoires de l'Union soviétique allait exiger la traduction des principaux écrits marxistes dans la langue de leurs habitants. Entreprise énorme, et qui pourrait se comparer en importance à la traduction biblique pour la christianisation. Mais si c'est bien là l'objectif primordial du Parti, il n'est pas le seul. Les peuples qui composent l'Union soviétique ne diffèrent pas que par la langue, ils accusent aussi un développement culturel et scientifique très inégal. Aussi, l'autre souci des dirigeants sera-t-il de répandre le savoir dans la langue de chacun, notamment en commençant par russifier systématiquement le patrimoine littéraire mondial.
\end{abstract}

\title{
DANS LA R.S.F.S. DE RUSSIE
}

Dès le lendemain de la Révolution, en 1918, une maison d'édition créée à Petrograd par Maksim Gorki à l'instigation de Lénine - La Littérature universelle s'était donné pour tâche de traduire quelque 1500 ouvrages puisés dans les littératures du monde entier. Le plan d'ensemble était éclectique: chefs-d'œuvre classiques, succès contemporains, prosateurs, poètes, romanciers, dramaturges, etc. Les traducteurs qui collaboraient à l'entreprise bénéficiaient de stages de formation, et les cours donnés à cette occasion par l'écrivain et critique Korneï Tchoukovski furent réunis en 1919 dans une brochure que l'on peut considérer comme l'embryon des écrits théoriques sur la traduction. Pendant les dix années de son existence, La Littérature universelle fit paraître cent vingt volumes traduits de Lesage, Voltaire, Balzac, Béranger, Mérimée, Hugo, Flaubert, Stendhal, Daudet, Rolland pour le français, Heine, Schiller pour l'allemand, Defoe, Swift, Sterne, Fielding, Thackeray, Byron, Dickens, Scott, Twain, Shaw pour l'anglais, Cervantès pour l'espagnol, etc. Ầ l'époque de la nouvelle politique économique (NEP, 19221928), de nombreuses maisons d'édition privées se lancèrent avec plus ou moins de bonheur dans la traduction, activité qui fut ensuite prise en main par de grandes entreprises d'État travaillant d'après un programme établi en fonction d'objectifs bien précis et faisant appel à des traducteurs de valeur. En 1928, Gorki publiait un article sur $L a$ Création littéraire des peuples de l'U.R.S.S. et, en 1934, le premier Congrès de l'Union des Écrivains soviétiques (fondée en 1932) soulignait la nécessité de connaître et de faire connaître (c'est-à-dire traduire) les littératures des diverses républiques de l'Union soviétique, de même que la nécessité de traduire les grandes oeuvres mondiales dans les langues de ces républiques. La vision marxiste des rapports entre peuples et cultures s'affirmait ainsi au niveau de la traduction. L'importance attachée par le marxisme, et par Staline en particulier, à l'influence de la langue fut déterminante pour l'orientation de la traduction et, par voie de conséquence, de la théorie de la traduction. L'expression «théorie de la traduction» fit son apparition en U.R.S.S. vers les années 1920-1930. En 1950, Staline lui-même publia un article sur les rapports entre marxisme et linguistique et, en 1954, le $2^{\mathrm{e}}$ Congrès de l'Union des Écrivains divisa la gent traductrice en deux camps, les tenants de l'exactitude linguistique et les défenseurs de la traduction artistique. L'Union soviétique, plus que jamais terre de traduction de par la volonté du régime et les impératifs de la gestion d'un État multilingue, devenait aussi le champ d'affrontement des théories de la traduction. Mais n'anticipons pas.

Que restait-il, dans ce brassage d'idées et de valeurs, de l'intérêt pour les Anciens? Rien de comparable à l'enthousiasme pour le monde gréco-latin qui suscita les grandes traductions du XIX ${ }^{\mathrm{e}}$ siècle. Certes, on trouve encore un poète et philosophe comme 
Vjatcheslav Ivanov (1866-1949) qui, ayant fait des études de philologie classique, traduisit des œuvres de Pindare, Bacchylide, Alcée, Sappho et Eschyle avant de préférer l'exil en Italie en 1917; ou un écrivain comme Vikenti Veresaev (1867-1945), médecin de son état et Prix Staline 1943, qui traduisit divers auteurs grecs et publia une nouvelle version de l'Iliade et de l'Odyssée (1945); ou un poète comme Aleksandr Kondratev qui traduisit divers poèmes de l'anthologie grecque; ou un Simon Markisch, fils du poète yiddish Perez Markisch, qui traduisit Plutarque. En vérité, c'est vers l'Occident que se tournent les yeux des nouveaux traducteurs.

Le français, langue de la patrie de la Révolution, gardait tout son prestige. Le poète Aleksandr Gatov (1899- ) se fit d'ailleurs l'interprète des poètes révolutionnaires français. Mais c'est toute la poésie de langue française qui semblait fasciner les traducteurs. Le poète et romancier Fedor Sologoub (1863-1927), qui d'une part traduisit Voltaire et Maupassant, s'intéressa spécialement à Verlaine et à Rimbaud. Verlaine fut encore traduit par le poète Valeri Briousov (1873-1924), qui en donna les Romances sans paroles (1894); Briousov qui, par la suite, fit partie de l'équipe qui anima La Littérature universelle, traduisit aussi des comédies de Molière, des poèmes de Baudelaire et du Belge Emile Verhaeren, ainsi que Pelléas et Mélisande (1907) du Prix Nobel belge Maurice Maeterlinck. D'autres interprètes de Verlaine furent le poète futuriste Nikolaï Aseev (1889-1963), par ailleurs traducteur de Mallarmé et de Viélé-Griffin; le poète et romancier Boris Pasternak (1890-1960), Prix Nobel 1958, qui s'était réfugié dans la traduction pendant une première période d'hostilité du régime à son égard; le poète et essayiste Pavel Antokolski (1896-1978), président du groupement des traducteurs au sein de l'Union des Écrivains, l'un des meilleurs connaisseurs de la poésie française, qui traduisit aussi Rouget de l'Isle, Béranger, Hugo, Barbier, Gautier, Baudelaire, Rimbaud, Laforgue, Apollinaire, Cocteau, Eluard, Aragon, Desnos et bien d'autres; le poète Benedikt Lifchitz, qui publia en 1937 une anthologie de la poésie française des romantiques aux surréalistes sous le titre Lyriques français des XIX ${ }^{e}$ et $X X^{e}$ siècles. Baudelaire trouva encore des interprètes dans le poète et prosateur Konstantin Balmont (1867-1943), qui traduisit aussi Paul Fort, ainsi que dans le critique et poète L. Kobilinski (pseudonyme: Ellis), qui fut aussi un admirable interprète du Belge Rodenbach et d'autres poètes français. Les Belges Verhaeren et Maeterlinck furent encore traduits respectivement par la poétesse Elisaveta Polonskaïa (1890- ), par ailleurs traductrice de Molière, pour le premier, par le romancier Alekseï Remizov (1877-1957) alors qu'il se trouvait en prison avant son émigration à Berlin en 1921, et par le poète Gheorghi Tchoulkov (1879- ) pour le second. Toujours au rayon de la poésie, Mikhail Kouzmine (1875-1938), poète de culture cosmopolite, traduisit des cuvres d'Henri de Régnier, Anatole France et Pierre Louys; Vsevolod Rojdestvenski (1895-) mit en russe des poèmes d'Henri de Régnier encore et de Théophile Gautier, dont le poète Nikolaï Goumiliov (1886-1921) fut le traducteur; Iliya Ehrenbourg (1891-1967) se fit l'interprète de Villon, du Bellay, Eluard, etc.; Efim Etkind (1918- ) traduisit des poésies de Barbier, mais aussi la tragédie Nicomède de Corneille; Wilhelm Levik (1906-1982) réunit dans son anthologie La Forêt magique (1975) des traductions de Ronsard et du Bellay à Baudelaire et Aragon. Du côté des prosateurs, Mérimée fut traduit par l'écrivain et homme politique Anatoli Lounatcharski (1875-1933), qui se fit en outre l'interprète de Romain Rolland, dont Mikhaîl Lozinski, contemporain de Pasternak et membre éminent de l'équipe de Gorki, traduisit encore le roman Colas Breugnon. Natalia Kassatkina, l'un des plus anciens membres de l'Union des Écrivains puisque son affiliation avait encore été signée par Gorki, russifia des œuvres de Théophile Gautier et de Maupassant. Le poète Vladimir Pjast (1866-1941) mit en russe des quvres de Stendhal et de Rabelais, dont Nikolaï Lioubimov, excellent spécialiste de la traduction prosaïque, traduisit admirablement Gargantua et Pantagruel. Á l'opposé, la version de la Chanson 
de Roland produite par B. Yarkho se heurta aux plus vives critiques quant à l'exactitude et au style.

La littérature allemande, elle aussi, demeurait un terrain d'exploration privilégié. Le poète symboliste Aleksandr Blok (1880-1924), qui collabora lui aussi à la maison d'édition de Gorki, se distingua par d'admirables traductions de Heine. Kassatkina traduisit des œuvres de Wilhelm Hoffmann, Heinrich Mann, Hans Fallada, Lion Feuchtwanger, Anna Seghers, Der geteilte Himmel de Christian Wolff, le roman Wilhelm Meister de Goethe. L'attirance de Goethe ne faiblissait pas. Il fut encore traduit par Sologoub, par ailleurs interprète de Kleist et de Heine; par Briousov, qui donna sa version du Faust, œuvre qui tenta encore Pasternak, traducteur aussi de Schiller, Heine, Rilke et du drame Der Prinz von Homburg de Kleist; par le romancier Alekseï Tolstoï (1883-1945), tenant de la traduction aristocratique et deux fois Prix Staline, qui en traduisit des poèmes; par le poète et critique Lev Ginsburg (1921-1980), longtemps président de la section moscovite de l'Association des Traducteurs et grand connaisseur de la poésie allemande, qui traduisit aussi excellemment les poètes baroques Fleming, von Birken, Gryphius et Hoffmann von Hoffmannswaldau que des poètes plus anciens comme Hartmann von Aue et Wolfram von Eschenbach ou des auteurs plus récents, de Schiller à Ringelnatz, Hauptmann, Brecht, Hermlin et Enzenberger, en passant par Chamisso, Heine et von Eichendorff; par le professeur Nikolaï Vilmont, également interprète de Schiller et de Thomas Mann. Le grand spécialiste de ce dernier fut toutefois l'épouse de Vilmont, Natalia Man, qui traduisit la plupart des romans: Die Buddenbrooks, Lotte in Weimar, Felix Krull, Die vertäuschten Köpfe, Der Tod in Venedig, etc., trouvant malgré tout le temps de s'intéresser encore à Grass et à Borchert. Ivanov mit en russe des poèmes de Novalis et de Stefan George; Lounatcharski, des œuvres de Hölderlin, Lenau, Spitteler, Hasenclever, Stucken; Balmont, des pièces des dramaturges Hoffmann et Sudermann; Etkind, des œuvres de Schiller, Hölderlin, von Platen, Storm, Fontane, Trakl, Becher, Brecht; Vladimir Stechenski, des romans de Wolfgang Koepper; Levik, qui traduisait Heine à seize ans déjà, des poèmes de Walther von der Vogelweide à Johannes Becher en passant par Goethe, Schiller et Heine, qu'il publia dans son recueil La Forêt magique (1975). Le Prix Nobel Heinrich Böll trouva des interprètes en Lev Kopelev (1912- ), spécialiste des littératures allemande et anglo-saxonne contemporaines, et en Ludmilla Tchornaïa, épouse de l'historien Daniel Melnikov, qui traduisit notamment Ansichten eines Clouns et Entfernung von der Truppe. Dans le domaine non littéraire, le critique et essayiste Iouli Aïkhenwald (1872-1928), avant d'être expulsé d'U.R.S.S., avait traduit des ouvrages du philosophe Arthur Schopenhauer.

Parmi les auteurs anglais les plus traduits, Shakespeare et Byron ont conservé une place de choix. Et leurs interprètes ne sont pas des moindres puisque le Prix Nobel Boris Pasternak lui-même traduisit non seulement Hamlet, King Lear, Othello et Romeo and Juliet, mais aussi des poésies de Byron, de Keats et de Shelley. L'écrivain et pédagogue Tatiana Gneditch traduisit le poème épique Don Juan de Byron pendant les vingt-deux mois de sa détention (1944-1946) et, après son retour à Léningrad, publia des traductions de Troilus and Cressida et Pericles de Shakespeare. Les Sonnets (1942) de Shakespeare furent traduits par le grand poète Samuil Marchak (1887-1964), Prix Lénine, qui fit ses études à Londres où il se passionna pour la traduction des «nursery rhymes» et qui fut aussi un interprète des poètes Byron, Blake, Shelley, Burns, Keats, Wordsworth, Tennyson, Kipling, Eliot, etc. Shakespeare fut encore traduit par le critique et théoricien littéraire Korneï Tchoukovski (1882-1969), celui-là même qui enseignait aux traducteurs de La Littérature universelle et qui, ayant acquis une bonne connaissance de la littérature anglo-saxonne pendant un séjour en Angleterre, se distingua également par des traductions de Defoe, Kipling, Chesterton, mais aussi des Américains Whitman, Twain et 
O'Henry; par l'excellent Lozinski, dont les Hamlet et autres versions sont d'une grande fidélité; par T. L. Chtchepkina-Koupernik, qui se fit remarquer pour ses interprétations de King Lear, The Tempest et A Midsummer Night's Dream; par la poétesse Polonskaïa, qui traduisit aussi Longfellow. Byron, pour sa part, trouva encore des interprètes en la personne du Prix Nobel Ivan Bounine (1870-1963), lui aussi traducteur de Longfellow; en Brioussov, qui traduisit en outre des cuvres d'Oscar Wilde et d'Edgar Poe (CEuvres complètes, 1911); en Eduard Bagricki (1895-1934), de son vrai nom Djoubine, qui fut aussi un interprète des poésies de Coleridge et de Scott; en Levik, qui dans son anthologie de poésie étrangère, La Forêt magique, a traduit non seulement Byron, mais aussi Shakespeare et d'autres. Poe fut traduit encore par le poète et critique B. Merejkovski et par Balmont, qui en donna les $F u v r e s$ complètes, ainsi que celles de Shelley. Parmi les traductions particulièrement réussies, il faut citer les Pickwick Papers de Dickens par Ivan Kachkine, auteur de nombreuses traductions en vers et en prose de l'anglais et théoricien de la traduction. Evgenia Kalachnikova (1906-1976), qui fit des études de littérature anglo-saxonne à l'Institut des Langues étrangères de Moscou, qui fut vice-présidente du Conseil de la Traduction littéraire d'U.R.S.S. et présidente de la section moscovite des traducteurs, s'impose comme une styliste brillante avec des traductions de Dickens, Thackeray, Shaw et, en particulier, des Américains Dreiser, Lewis, Hemingway, Steinbeck, Scott Fitzgerald, Aldridge, Caldwell, O'Connor, Henry James, etc. Et que dire de Lena Karpov, traductrice de The Mysterious Stranger (1970) de Mark Twain ainsi que d'cuvres du romancier John Updike et du dramaturge Eduard Albee, qui bien qu'immigrée aux États-Unis obtint en 1970 le Prix de Traduction Pouchkine décerné par l'Institut Philologique de Moscou; il est vrai qu'elle a servi aussi les lettres russes en traduisant en anglais Balzac and Dostö̈evsky (1972) de Leonid Grossman, Siberian Notebook (1973) de Nikolaï Polevoï, Convoy (1976) d'A. Bek, ainsi que des poésies de Pouchkine, de Bella Akhmadoulina et d'autres.

Comparées à la profusion des traductions de l'allemand et de l'anglais, les langues latines autres que le français font à nouveau piètre figure. La plupart des traducteurs qui s'y intéressent sont aussi des interprètes d'autres langues. Il y a Kouzmine qui, ayant voyagé en Italie, a traduit divers poètes de ce pays; il y a Ivanov qui, réfugié en Italie, a mis en russe les poésies de Pétrarque; il y a surtout Lozinski, à qui l'on doit des traductions de Gabriele d'Annunzio et une admirable version de la Divina Commedia (19401945) de Dante dans le mètre de l'original, pour laquelle il obtint en 1945 le Prix Staline. Lozinski a traduit aussi de l'espagnol, notamment les comédies de Lope de Vega ainsi que des œuvres de divers poètes et romanciers. L'Espagne a encore tenté Pjast, Balmont, Polonskaïa et Lioubimov, tous déjà traducteurs du français, le premier russifiant des œuvres de Cervantès, de Tirso de Molina et de Calderon, les deux suivants des pièces de Calderon également, le dernier à nouveau Cervantès. Du portugais, Levik a donné des poèmes de Camoëns dans sa Forêt magique.

D'un autre côté, l'éventail des langues traduites s'est élargi. Du hongrois, la poésie de Sandor Petöfi a connu des traductions de Sologoub, de Marchak, de Pasternak, de Levik et de Lounatcharski, ce dernier travaillant sur des versions allemandes de Neugebauer et Steinbach. Du polonais, Pasternak encore a traduit le poète Juliusz Slowacki; Levik a donné divers poèmes de Mickiewicz dans sa Forêt magique; Sviatoslav Sviatzi, le spécialiste de cette langue, en a publié de nombreuses traductions qui lui ont valu en 1970 le Prix de la Société des Auteurs polonais. Du norvégien, Balmont a traduit Henrik Ibsen, lequel a trouvé encore une interprète en Tatania Gneditch qui s'est aussi consacrée à des poètes modernes comme Otto Gelsted. Le romancier Mikhail Zochtchenko (1895-1962) a traduit en de nombreuses langues, parmi lesquelles le finnois, mais très certainement sur des versions intermédiaires. 
L'exploration des lettres exotiques s'est poursuivie de même. L'orientaliste V. Chileico, second mari de la poétesse Akhmatova, a traduit l'épopée de Gilgamesh (1919), le chef-d'œuvre de la littérature suméro-akkadienne. En 1929, M. A. Salié a publié une version des Mille et une nuits qui réussit le tour de force de respecter les rythmes de la prosodie arabe jusque dans les citations poétiques dont le texte fourmille. Du sanskrit, l'infatigable Balmont a traduit le poète indien Kâlidâsa $\left(\mathrm{I}^{\mathrm{er}} \mathrm{s}\right.$.), très certainement sur une version occidentale puisqu'il ignorait la langue de l'original. Tel n'était pas le cas de l'orientaliste V. Kalianov qui publia en 1950 une traduction en prose du premier livre de la Mahâhhârata (II $\mathrm{e}$ s. av. J.-C.) sous la direction de l'indianiste P. Barannikov, lui-même auteur d'une brillante version du Râmâyan de Tulsi-Das; les livres III, V et VI de la Mahâbhârata ont été traduits en vers blancs de 1955 à 1957 par le médecin B.L. Smirnov qui, parallèlement à la neuropathologie, a consacré toute sa vie à l'étude de la civilisation indienne et de la littérature sanskrite. Du bengali, Pasternak a traduit des poèmes de Rabindranath Tagore, en se servant indubitablement d'une version anglaise. Le sinologue A. Chtoukine a donné, en collaboration avec la poétesse-traductrice A. Adalis, une nouvelle interprétation en vers du Che-King (Livre des vers, 1957), ouvrage classique de la dynastie Tchéou (1050-249 av. J.-C.). La poétesse Anna Akhmatova (1889-1966) a traduit des poésies des langues les plus diverses, y compris le coréen et l'égyptien, et s'il est vraisemblable qu'elle ne connaissait pas plus ces langues que Pasternak ne savait le bengali, ces recréations poétiques prouvent à tout le moins que la curiosité des traducteurs est sans limites.

Dans le même temps s'amplifiait le mouvement de traduction des littératures de l'Union soviétique. Le chef-d'œuvre de la poésie géorgienne du XII' siècle, Le Chevalier à la peau de tigre de Chota Rousthaveli, a été traduit par le prolifique et approximatif Balmont, par P. Petrenko en 1938, par G. Cagareli en 1953, par Nikolaï Zabolotski, qui s'est fait aussi l'interprète d'autres poètes géorgiens. De même, Pasternak, toujours aussi personnel dans une totale fidélité, a mis en russe des poésies de Barathachvili, Orbeliani, Pachavela, Tabidze, Jachvili, etc. La poétesse Bella Akhmadoulina (1937- ), spécialiste de la poésie géorgienne, a réuni ses traductions dans le volume Sny o Grusii. Stichi i perevodi (1979). L'époque arménienne David de Sassoun $\left(\mathrm{XIII}^{\mathrm{e}} \mathrm{s}\right.$.) a été traduite, notamment, par Sergeï Chervinski et par Briousov, qui a donné en outre d'autres Poètes arméniens (1916). Vladimir Rossels, théoricien de la traduction, a mis en russe des œuvres ukrainiennes modernes; Zabolotski, des poèmes ukrainiens, mais aussi tadjiks et ouzbeks. L'année 1951 a vu paraître une Anthologie de la poésie tadjik où figuraient les œuvres classiques de Roudaki, de Firdousi, de Khayyam et d'autres grands poètes persans et tadjiks. Les poètes Aleksandr Gatov (1899-) et Nikolaï Uchakov (1899- ) se sont également signalés comme traducteurs de poètes de différentes Républiques de l'Union soviétique.

On a continué aussi à retraduire en russe moderne des textes anciens: Chervinski, M. Tarlovski, Nikolaï Pavlov (1805-1864), Ivan Novikov (1877-1959) ont donné chacun leur version du Dit de la campagne d'Igor (XII ${ }^{\mathrm{e}} \mathrm{s}$.), tandis que Kouzmine rajeunissait des textes slavons du XV siècle, D. Lichatchov et $\mathrm{B}$. Romanov La Chronique russe du XIV ${ }^{e}$ siècle (1950), N. Cajev Le Voyage au-delà des trois mers d'Anathase Nikitine (1960), B. Larine des Récits russes des $X V^{e}$ et $X V I^{e}$ siècles (1958).

C'est à l'intérieur des frontières de l'Union soviétique que les échanges interlinguistiques ont pris une envergure sans pareille. Avec plus de deux cents langues et plus de vingt littératures nationales, l'U.R.S.S. est devenue le pays où l'on publie le plus grand nombre de traductions et dans le plus grand nombre d'idiomes. Si depuis 1917 un Victor Hugo a été traduit en 40 langues de l'Union, un Shakespeare en 20, un Maupassant en 20, c'est encore peu en regard des auteurs nationaux, puisque le Russe Pouchkine, l'Ukrainien 
Chevtchenko et le Kazak Djamboul l'ont été respectivement en 76, 33 et 21 langues. Cela donne la mesure de l'activité traduisante dans les diverses Républiques.

\section{DANS QUELQUES AUTRES RÉPUBLIQUES}

Il n'est donc pas sans intérêt de s'attarder un moment à quelques-unes de ces Républiques, au développement culturel très inégal et dont certaines n'ont eu que très tard une langue écrite et littéraire. Celles qui avaient déjà connu très tôt leur âge d'or, telles la Géorgie et l'Arménie, ont maintenu leur tradition de nation traductrice en lui donnant une nouvelle vigueur; dans d'autres, comme par exemple les Républiques baltes, la traduction n'a pu prendre qu'un essor beaucoup plus tardif.

En Géorgie, après la traduction du roman Visramiani ( $\mathrm{XII}^{\mathrm{e}} \mathrm{s}$.), la littérature persane continua d'exercer son influence pendant de nombreux siècles. Vers le $X^{\mathrm{e}}$ siècle, la traduction, très libre, du Rostomiani prit valeur d'épopée nationale. Un égal succès couronna les traductions des poèmes Baramguriani et Baramgulijamiani (XVIII ${ }^{\mathrm{e}} \mathrm{s}$.), bien qu'elles fussent davantage des imitations que de véritables traductions. Le $X V I^{\mathrm{e}}$ siècle avait déjà connu un imitateur prolifique en la personne du roi Teimuraz $\mathrm{I}^{\mathrm{er}}$. Un autre roi, Vakhtang VI (1711-1737), neveu du moine Saba Orbeliani qui composa le dictionnaire de la langue géorgienne, traduisit encore du persan Kalila-va-Dimna, considéré comme le meilleur spécimen de la littérature géorgienne ancienne. Parmi les autres œuvres importantes traduites à cette époque, il faut citer pêle-mêle le Testament de Basile de Macédoine (1739) par le prince Alexandre, les Euvres de Marc-Aurèle par le recteur David, la Dialectique d'Aristote par le catholicos Antoni $\mathrm{I}^{\mathrm{er}}$, etc. Le prince David, petit-fils du roi de Khartlie Irakli II (1762-1798), traduisit l'Histoire d'Alexandre de Macédoine et l'Histoire d'Égypte d'Hérodote; connaissant aussi le français, il mit encore en géorgien l'Esprit des lois de Montesquieu. Au XVIII ${ }^{\mathrm{e}}$ siècle, la Géorgie se lassa de l'Orient et se tourna franchement vers la culture occidentale sous l'influence des rationalistes français. Le poète Aleksandr Tchavtchavadze traduisit Esope et Pouchkine, mais surtout des auteurs français, de Voltaire à Hugo en passant par Racine, Corneille et La Fontaine. Le dramaturge Ghiorghi Eristhavi (1811-1864), créateur du théâtre national dans son pays, se passionna pour Racine, dont il traduisit les tragédies. Le poète romantique Grigol Orbeliani fut le premier interprète de Goethe, dont il donna le Wanderers Nachtlied (1865) sur la version russe de Lermontov. La tragédie Egmont, du même Goethe, fut traduite en 1869-1870 par M. Khoudadov et en 1873 par Ghiorghi Tsereteli. D'autres interprètes de Goethe furent A. Tchitchinadze et G. Iosteliani, qui en rendirent le Reinke Fuchs respectivement en 1885 et 1895 . Vers 1870 , l'écrivain Ivane Matchabeli et le poète Ilia Tchavtchavadze collaborèrent à la traduction du King Lear de Shakespeare; Matchabeli, fondateur de l'école de la traduction réaliste en Géorgie, donna par la suite la totalité de l'œuvre shakespearienne avec une maîtrise remarquable. Au tournant du siècle, les romans d'ErckmannChatrian furent traduits du français par I. Matchavariani, ceux de Maupassant par T. Sakhokia. De l'espagnol, N. Avalichvili traduisit Cervantès. Un peu plus tard, I. Akhalchenichvili traduisit des auteurs russes comme Dostö̈evski et Tchekhov, mais aussi Die Leiden des jungen Werthers (1909) de Goethe. Viktor Kachniachvili s'est également spécialisé dans la traduction de l'allemand, de même que le germaniste I. Kemertelidze, qui a traduit Wilhelm Meisters Wanderjahre, Die Wahlverwandtschaften et Faust (1983) de Goethe. Dans le domaine anglais, Ghivi Gatchetchiladze (1914-1974), par ailleurs brillant théoricien, a laissé de remarquables traductions des CEuvres lyriques de Byron (1938), de Poètes anglais (1942), de Ballades populaires anglaises (1942) et des Sonnets (1960) de Shakespeare. Du hongrois, Nodar Gourechidze a traduit le poème dramatique La Tragédie de l'Homme (1970) d'Imre Madach. Ainsi, jusqu'à nos jours, la Géorgie a maintenu vivace sa tradition de nation traductrice. 
En Arménie de même, l'activité traduisante n'a pas connu d'interruption au cours des siècles. À la période hellénisante succéda la période dite cilicienne, du nom de la Cilicie ou Petite Arménie, royaume méridional constitué en 1198 avec le soutien des croisés après l'invasion du pays par les Seldjoukides. La traduction de cette époque, qui couvre les XII et XIII ${ }^{\mathrm{e}}$ siècles, se caractérise d'une part, par la méthode utilisée: des Grecs ou des Syriens faisaient une première version littérale de la langue originale et des Arméniens en assuraient la mise en forme littéraire, et, d'autre part, par son côté pragmatique: il fallait répondre aux besoins immédiats de l'État cilicien. On se mit donc à traduire du syriaque, du grec, du vieux français et de l'arabe toute une série d'ouvrages pratiques. Ainsi, dans le domaine du droit, le Code de lois syrio-romain, le Recueil de lois byzantin, les Assises d'Antioche dues à Sempad le Connétable (XIII ${ }^{\mathrm{e}}$ s.) et, dans le domaine des sciences, les écrits anatomiques et médicaux d'Abou Saïd et d'Ichogh, le manuel vétérinaire Soins des chevaux de Faradj le Syrien, la Géoponique, encyclopédie des connaissances agricoles médiévales, des ouvrages sur l'astronomie, la fonte de l'acier, la fabrication des sabres, etc., certains de ces travaux étant ordonnés par le roi Héthoun $\mathrm{I}^{\mathrm{er}}(+1270)$ en personne. Ces traductions pratiques utilisaient l'arménien moyen, compris par tous, contrairement aux traductions ecclésiastiques qui étaient rédigées en arménien classique ancien. Le XII ${ }^{\mathrm{e}}$ siècle n'avait d'ailleurs pas abandonné tout à fait la traduction des textes sacrés ou patristiques, puisque des hommes comme le patriarche Grégoire III (1092-1166), le catholicos Nersès IV (+ 1173), célèbre comme poète et philologue, et l'évêque Nersès de Lambron, écrivain théologique, poète et traducteur s'y sont adonnés. Nersès de Lambron, en particulier, se distingua par des traductions du syriaque, du grec et du latin: Sur la vie des Pères de l'Italie du pape Grégoire, la Règle de saint Benoît, des canons ecclésiastiques, des épîtres, des livres liturgiques, etc. La proximité de la Syrie favorisa l'apparition de nombreuses traductions du syriaque: la Chronique de Michel le Syrien, due à la collaboration du prêtre et savant Ichogh et de Vardan l'Oriental, le Commentaire des Psaumes de Daniel de Salah, les Homélies de Jacques de Sarug, la Vie d'Ephrem le Syrien, les Actes du martyre de Serge traduits en collaboration par le moine syrien Michel et l'évêque Nersès, etc.

Dans le même temps, la partie septentrionale de la Grande Arménie, alors sous l'influence de la Géorgie, développait une activité de traduction propre, qui mettait en évidence un Siméon de Peghendzahank, lequel traduisit du géorgien les Éléments de théologie de Proclus Diodochus, la Source de connaissance de Jean de Damas, l'Échelle de l'Exode divin de Jean de Sinaï, une Histoire de la Géorgie et le Bréviaire grec. Dans le domaine profane, le poète Khatchatour de Ketcharis (XIII ${ }^{-}$XIV $^{\mathrm{e}} \mathrm{s}$.) donnait une nouvelle version du Roman d'Alexandre pour l'adapter aux règles de la morale chrétienne; les Préceptes d'Anôcharvân, attribués au roi Khosrô ${ }^{\mathrm{er}}$ furent traduits à la même époque. Ces traductions annonçaient déjà celles de la période uniate (XIV ${ }^{\mathrm{e}} \mathrm{s}$ ), qui marqua la volonté du peuple arménien de reconquérir sa liberté avec l'aide de la papauté.

Dans les centres culturels du mouvement uniate, principalement les monastères de Tzortzor et de Kerna, des traducteurs comme Jean de Tzortzor, Jean et Jacques de Kerna, travaillant en équipe avec des missionnaires comme Barthélémy de Bologne et Pierre d'Aragon, mirent du latin en arménien un grand nombre de livres liturgiques, d'ouvrages théologiques et exégétiques, philosophiques et scientifiques, parmi lesquels la Somme théologique, Des Mystères de l'Église et Des Vertus de l'âme de Thomas d'Aquin, le Bref exposé des vérités théologiques d'Albertus Magnus, le Livre des six principes du théologien français Gilbert de La Porree, le Commentaire de l'Évangile selon saint Jean et le Commentaire de l'Épître de Paul aux Juifs de l'exégète français Nicolas de Lyre, le Commentaire de l' Hexaméron, le Bref exposé de la dialectique et le Livre des sermons du dominicain Barthélémy de Bologne, la Brève analyse des Catégories d'Aristote, le Bref 
exposé du commentaire sur l'Introduction de Porphyre de Pierre d'Aragon, etc. L'historien uniate Nersès Parlianentz traduisit vers 1340, pendant un séjour en Avignon, alors ville papale, la Chronique des souverains pontifes du chroniqueur dominicain Martin le Polonais.

Après une éclipse de près de deux siècles, qui vit néanmoins l'éditeur Jean de Terzyn traduire sur une version italienne le roman de chevalerie Histoire de Paris et de Vienne (1587), l'activité de traduction reprit au XVII ${ }^{\mathrm{e}}$ siècle grâce aux communautés arméniennes de l'étranger. Les grands centres d'imprimerie installés à Marseille par les Terzyn et les Voskan, à Amsterdam par les Vanandetsi contribuèrent grandement à la diffusion des traductions qui devaient initier le peuple arménien à la culture européenne et au progrès des sciences. Au XVIr e siècle, Voskan d'Erevan traduisit du latin l'Art de la grammaire, les Éléments de logique, un dictionnaire philosophique et divers livres bibliques. Jean d'Ancyre a laissé des traductions de la Géographie latine et de la Cosmographie de Pierre Appianus, de la Géographie de Ptolémée, de l'Histoire des mondes, de la Physiognomique de Jean-Baptiste Borta, etc. Stéphane de Pologne traduisit l'Histoire de la guerre de Judée de Flavius Josèphe, la Métaphysique d'Aristote, le Livre des causes de Proclus Diodochus, le Grand miroir, les œuvres de Denys l'Aréopagite, etc. Parmi les traductions de Jean de Holov, il faut mentionner l'Imitation de Jésus Christ de Thomas à Kempis, l'Explication des psaumes spirituels de David, la Physiognomique, un Jardin spirituel, un Art de compter, etc. Dans le domaine profane, Jacques de Toklat traduisit d'une version latine le roman oriental Kalila et Dimna (1614). Au XVIII' siècle, le travail de traduction se concentra surtout dans les foyers d'imprimerie arménienne de Venise et de Constantinople, et les principaux acteurs avaient nom Pierre Moukhoubian, Athanase Merissian, Vrtanès Askerian, Margan Chahrimanian, etc.

Au XIX ${ }^{\mathrm{e}}$ siècle, le mékhitariste de Venise Arsène Bagratouni (1786-1866), helléniste distingué et restaurateur de l'arménien classique, traduisit des œuvres de Sophocle et Homère, mais aussi de Virgile, ainsi que le Paradise Lost de John Milton. Le fondateur de la nouvelle littérature arménienne, Khatchatour Abovian (1809-1848), qui étudia l'allemand pendant six ans à Dorpat (Tartu), fut le premier traducteur de Goethe, dont il donna le poème Der Erlkönig (1831), à côté des ballades Ritter Toggenburg et Die Bürgschaft (1831) de Schiller. Des traducteurs de Goethe se sont ensuite succédé tout au long du siècle et jusqu'à nos jours. Le philologue Mkrtych Emine est l'auteur d'une anthologie intitulée Fragments choisis des ceuvres d'écrivains anciens et nouveaux (1849), qui contient une traduction du Prometheus. Un autre philologue, M. Mamourian, publia une traduction de Die Leiden des jungen Werthers (1866) et Theodoros Terzian fut le premier interprète de Faust, dont il fit paraître des fragments en 1881. Rheteos Berberian traduisit le poème Hermann und Dorothea (1883), Philipos Vartanian la tragédie Clavigo (1883) et Amayak Majinian la tragédie Egmont (1889). Au tournant du siècle, Levon Tigranian mit en arménien Hermann und Dorothea (1900) et le drame Torquato Tasso (1900), après avoir déjà donné deux versions libres du Faust (1891), œuvre dont Guevorg Barkhoudarian publia une nouvelle interprétation en 1902. La même année, Guevorg Altounian traduisit la tragédie Stella (1902), suivie de Iphigenie auf Tauris (1914). Le roman de Werther fut retraduit en 1921 par Zare Nemtse. Grigor Akop interpréta librement Faust (1929), ainsi que les drames Goetz von Berlichingen, Clavigo, Stella et Die Geschwister, réunis en volume en 1930. Le poète Y. Tcharents, outre une traduction inachevée de Faust, a laissé des transpositions du Wanderers Nachtlied et d'autres poèmes dans son recueil Le Livre de la voie (1933). D'autres poésies ont paru en 1946 dans un recueil d'Akop Aroutounian. L'historien de la littérature arménienne, Akop Akopian, a traduit Torquato Tasso (1981) et Dichtung und Wahrheit (1983), mais aussi les Gespräche mit Goethe (1975) de Johann Eckermann. En Arménie, comme en Géorgie, la 
traduction a donc toujours été un instrument culturel de premier plan et la littérature de traduction y a pendant près de quinze siècles cheminé de concert avec la littérature originale. L'Arménie est aussi le seul pays au monde où les premiers traducteurs, canonisés par l'Église locale, sont honorés comme des saints, dont la fête est célébrée officiellement en octobre de chaque année.

En Ukraine, le rôle de la traduction n'a pas toujours été ce qu'il est aujourd'hui. Il est vrai que la langue ukrainienne ne s'est détachée du russe qu'après la prise de Kiev par les Mongols (1240), qui sépara le développement culturel de l'Ukraine de celui de la Russie, et que l'ukrainien littéraire ne se forma qu'aux $\mathrm{XVI}^{\mathrm{e}}-\mathrm{XVII}$ e siècles. Encore, son expansion fut-elle entravée en Ukraine occidentale par la concurrence du polonais et, en Ukraine orientale, par un décret de Pierre le Grand (1720) qui interdisait les publications en ukrainien à moins qu'elles ne fussent de nature religieuse. De sorte qu'il fallut attendre le XVIII ${ }^{\mathrm{e}}$ siècle pour voir apparaître les premières ouvres originales. Rien d'étonnant, dès lors, si l'activité traduisante, elle aussi, se soit manifestée assez tardivement, avec une Enéide travestie (1798) du père de la littérature ukrainienne moderne, Ivan Kotliarevski (1769-1836). Un peu plus tôt, vers 1880, la romancière Marja Marko-Vovtchok (18341907), de son vrai nom Markovitch, avait entrepris de traduire divers auteurs étrangers, en particulier les romans de Jules Verne. L'écrivain et patriote Ivan Franko (1856-1916), auteur de nombreuses traductions des littératures européennes, parmi lesquelles des poésies de Heine, fut aussi le premier à traduire en ukrainien des passages de Das Kapital de Karl Marx et de l'Anti-Dühring de Friedrich Engels. Heine fut encore traduit par la poétesse Lessia Oukraïnka (1871-1913), de son vrai nom Laryssa Kossatch-Kvitka, et par Pavlo Hrabovski (1864-1902), sans aucun doute le traducteur le plus prolifique et le plus universel de son temps. Poète lui-même, Hrabovski fut arrêté à de multiples reprises pour ses idées révolutionnaires dès l'âge de dix-huit ans, et c'est en prison qu'il entreprit l'étude de l'allemand, de l'anglais, du français et se mit à traduire des poèmes: le Faust de Goethe, The Prisoner of Chillon de Byron, Eugène Onéguine de Pouchkine, The Song of the Shirt de Thomas Hood, mais aussi des poètes italiens, bulgares, serbes, croates, slovaques, tchèques, etc., avec l'aide de codétenus qui lui fournissaient des versions russes intermédiaires. En 1897, il publia Destin, un recueil de cent six poèmes traduits de Burns, Scott, Wordsworth, Shelley, Tennyson, Poe, Longfellow pour l'anglais, de Baudelaire, Verlaine pour le français, de Lenau, Goethe pour l'allemand, mais encore d'auteurs polonais, hongrois, danois, norvégiens, géorgiens et arméniens. Un deuxième volume de traductions suivit en 1898 sous le titre Luth, mais son dernier recueil, Vague (1899), qui comprend cent trente-huit poèmes de quatre-vingt-huit auteurs, ne fut autorisé à paraitre que cinquante ans après sa mort.

L'avènement du régime soviétique a donné l'impulsion décisive à une activité intense sur tous les fronts de la traduction. Un écrivain comme Mikola Lukasch (1919- ), qui découvrit sa vocation de traducteur en 1947 alors qu'il étudiait à l'Institut pédagogique des Langues étrangères de Kharkov, est un autre bel exemple d'universalité. Après avoir déjà traduit des poèmes de Heine et des passages du Faust de Goethe à l'âge de quatorze ans, il publia en 1955 son intégrale de Faust, qui est une réussite remarquable. Parmi ses autres traductions, toutes de qualité, il convient de citer le Décaméron de Boccace, le Don Quichote de Cervantès, Madame Bovary de Flaubert, Peer Gynt du Norvégien Ibsen, La Tragédie de l'Homme du Hongrois Madach, des poèmes de Schiller, de Lope de Vega, de Garcia Lorca, de Mickiewicz, etc. Au total, il traduisit ainsi poésie, prose et théâtre d'une vingtaine de langues différentes: français, anglais, allemand, russe, biélorusse, polonais, yiddish, italien, espagnol, portugais, latin, tchèque, slovaque, serbe, croate, slovène, hongrois, bulgare, norvégien, danois. Le poète Maksim Rylski (18951964) a lui aussi laissé de méritoires traductions du français (La Pucelle de Voltaire), de 
l'anglais (King Lear de Shakespeare), du russe (Eugène Onéguine de Pouchkine), du polonais (Pan Tadeusz de Mickiewicz); il s'est en outre signalé par un ouvrage de théorie, L'Art de la traduction (1975). Parmi les traducteurs de l'allemand se sont distingués un Evgen Popovitch, qui s'est montré un subtil interprète du roman Haus ohne Hüter (1969) de Heinrich Böll, ainsi que des œuvres de Thomas Mann et Hermann Hesse; un poète comme Mikola Bajane, qui a traduit de Rilke les Duineser Elegien et Die Sonette an Orpheus (1974) mais a donné aussi du poème géorgien Le Chevalier à la peau de tigre, composé au XII ${ }^{\mathrm{e}}$ siècle par Chota Rousthaveli, une version pour laquelle il créa une forme et un mètre qui ont enrichi la poésie ukrainienne; un Vladimir Mitrofanov, qui s'est révélé un talentueux interprète de Bertold Brecht; un Oleh Zujevski ou un Michaillo Orest, qui ont traduit des poésies de Stefan George, etc. Dans le domaine anglais, Shakespeare attire toujours beaucoup de traducteurs: l'excellent Iouri Havruk, Grigori Kotschur - qui est l'auteur d'une dixième et remarquable version de Hamlet, Dmitro Palamartchouk - qui a traduit les Sonnets et qui de plus s'est fait l'interprète de Byron. D'autres traducteurs de l'anglais sont le poète Vitali Korotitch, qui s'est intéressé à Thomas Eliot, à Walt Whitman et aux poètes américains contemporains, tandis que Mitrofanov s'attachait aux prosateurs; Vassil Myssik, auteur de brillantes traductions de Burns mais aussi d'Omar Khayyam par le biais de l'anglais; Iouri Lisniak, qui a traduit des romans de Dickens, mais aussi d'Anatole France. Ont encore traduit du français un Feofan Sklar, auteur d'une version des œuvres lyriques de Ronsard; un Mikhaill Moskalenko, qui a publié un recueil de poèmes de Paul Eluard (1975); un poète comme Ivan Dratch, autre interprète d'Eluard, mais aussi de Baudelaire; un Mikola Terechtchenko, auteur d'une anthologie intitulée La Constellation de la poésie française, qui contient des traductions de Villon à Eluard, etc. Dans le domaine italien, Evgen Drobiazko a réalisé la première intégrale en ukrainien de la Divina Commedia (1977) de Dante. Le poète Dmitro Pavlitchko, traducteur du poète bulgare Khristo Botev, est aussi l'auteur des premières versions ukrainiennes des œuvres du poète cubain José Marti (1977). Les anciens ne sont pas oubliés pour autant puisque le polyglotte Boris Ten a traduit en hexamètres l'Iliade et l'Odyssée d'Homère, comme pour illustrer la volonté des traducteurs ukrainiens d'embrasser tous les horizons afin de combler au plus tôt le retard pris sur les autres langues de culture.

La Biélorussie et les Républiques baltes ont connu une évolution assez semblable, dans la mesure où le biélorusse, le lituanien, le lette et l'este sont devenus ou redevenus langues nationales et littéraires après la Révolution. Le biélorusse, troisième branche du slave oriental à s'être détachée du russe au XIII ${ }^{\mathrm{e}}$ siècle, avait pourtant connu un Moyen Âge assez brillant alors qu'il était langue officielle du Grand-Duché de Lituanie. L'érudit Frantsisk Loukitch, dit Skorina, traduisit la Bible (1517-1519) et les Actes des Apôtres (1525), dont il assura lui-même l'impression dans la première imprimerie qu'il avait installée à Vilna (Vilnious) en 1525. La décadence vint avec le rattachement du pays au Grand-Duché de Pologne (1569), et elle dura jusqu'au XIX ${ }^{\mathrm{e}}$ siècle. Ce n'est que peu avant la Révolution, en 1906, que fut lancée la première revue de littérature et, malgré une certaine renaissance, la littérature biélorusse reste la moins développée des littératures slaves. Cette situation se répercute sur la littérature de traduction. En Lettonie de même, bien que le premier document en lette soit une traduction du Notre Père datant de 1526, et bien que la Réforme luthérienne eût déjà fixé la langue écrite, le lette ne devint langue nationale et littéraire qu'au XIX ${ }^{\mathrm{e}}$ siècle et la littérature, tant originale que traduite, ne connut qu'un essor tardif. Le lette, comme le lituanien, appartient au groupe baltique du balto-slave. En Lituanie, comme en Lettonie, ce sont les ouvrages religieux de la Réforme et de la Contre-Réforme qui ont fixé la langue écrite, et la première traduction en lituanien est celle d'un texte de Luther en 1547. L'activité littéraire fut toutefois lente à 
se développer, entravée encore de 1864 à 1904 par l'interdiction officielle d'imprimer en caratères latins. Il fallut la conjonction d'une liberté de presse retrouvée et de la rénovation de la langue par le philologue Antanas Baranauskas (1835-1902) pour voir un véritable épanouissement littéraire, qui s'accompagne aussitôt d'une grande activité de traduction. Le seul Goethe, pour prendre un exemple significatif, eut l'honneur d'une pléthore de traductions, qui se poursuivent à ce jour. L'écrivain Povilas Matulionis, en publiant une partie du Faust en 1888, fut le premier traducteur de Goethe en Lituanie, suivi de peu par le poète Jonas Macys-Kekstas - par ailleurs traducteur de Heine et de Lermontov - qui en donna le poème Des Wanderers Nachtlied (1892). Un autre poète, Mykolas Vaitkus, traduisit pour la première fois une ballade, Der Erlkömig, en 1904. Après 1930, année qui marqua un grand essor de la littérature, le rythme des traductions s'accéléra également. En 1932, le germaniste P. Jaucys publia la première traduction de Die Leiden des jungen Werthers, I. Adamsas la première du drame Egmont, A. Tyruolis un recueil de poésies et de ballades. Quelques années plus tard, c'est le poème Hermann und Dorothea (1939) qui vit le jour dans la première version de J. Zekevicius. Plus près de nous, une nouvelle version de Werther parut en 1963 sous la plume d'E. Vengrenie. Enfin, l'écrivain Aleksys Churginas obtint pour sa première traduction intégrale du Faust I le Prix d'État de la R.S.S. de Lituanie. Il en avait publié des extraits en 1938, mais l'œuvre complète ne parut qu'en 1960, suivie en 1978 de l'ensemble Faust I et II, que la critique salua comme une recréation magistrale, d'un grand souffle poétique et d'une profonde compréhension de l'original. En Estonie encore, c'est la Réforme luthérienne qui fixe la langue écrite et, parmi les premiers ouvrages imprimés, il y eut une traduction en este de la Bible. L'este est la troisième langue de culture de la famille finno-ougrienne et, pourtant, une création littéraire profane n'apparut qu'au XIX ${ }^{e}$ siècle et encore fut-elle bridée par les Russes jusqu'à la fin du siècle. Comme en Lituanie, il fallut attendre en 1905 pour assister à un renouveau littéraire, qui ne connut son plein épanouissement qu'après la Révolution. Elle se doubla d'une activité traduisante dont on peut mesurer l'importance en suivant, une fois encore, les interprètes de Goethe. Au XIX siècle déjà, le folkloriste Friedrich Kreutzwaldt (1803-1882) traduisit Reineke Fuchs, tandis que le critique Anton Jurgenstein donnait une première version de Faust, jugée vieillie déjà de son vivant. Il allait s'écouler un demi-siècle avant que le poète Ants Ovas ne publie une intégrale de Faust I et II (1946), dont le poète August Sang fit paraître une version nouvelle en 1967 avant de traduire encore la tragédie Egmont (1982). Cette dernière avait déjà été traduite en 1924 par la poétesse Anna Haava et, quelques années auparavant, c'est Die Leiden des jungen Werthers (1920) qui avait été mis en este par Jaan Kärner. En 1958, Leida Kibuvits traduisit Wilhelm Meisters Lehrjahre et, en 1959, Wilhelm Meisters Wanderjahre. Mais si Goethe reste d'actualité, on n'en oublie pas pour autant les autres œuvres de la littérature allemande puisqu'une poétesse comme Maria Under (1883-1980) se fait l'interprète non seulement de Goethe mais aussi de Schiller, de Nietzsche, de Hauptmann, de von Hofmannsthal et de Rilke, traduisant encore les tragédies Sappho (1921), Medea (1927) et Die Jüdin von Toledo (1930) de l'Autrichien Franz Grillparzer et qu'en 1978 un Rein Sepp obtient le Prix de Traduction de la R.S.S. d'Estonie pour son interprétation de l'épopée Das Nibelungenlied. Les autres langues ne sont pas davantage négligées, puisqu'un Georg Meri, grand spécialiste de Shakespeare, en traduit l'œuvre complète en sept volumes, en collaboration avec Harald Rajamets; qu'un romancier comme Anton Tammsaare (1878-1940) traduit encore de l'anglais des cuvres de Conrad, Galsworthy, Lawrence, Shaw, Wilde, et du russe des romans de Dostoïevsky et de Gontcharov; qu'une Maria Under traduit du français des œuvres de Baudelaire, Claudel, Maeterlinck, du russe des poésies de Lermontov, Blok, Akhmatova, Pasternak, et du norvégien des pièces d'Ibsen; qu'un Jaan Kross met en este le poème dramatique $L a$ 
Tragédie de l'Homme (1970) du Hongrois Imre Madach; qu'un Haljand Udam traduit directement du persan les cuvres des poètes Khayyam, Saadi et Roudaki; ou qu'un Linnart Mäll transpose directement du pâli le Dhammapada (1977), l'ouvrage d'éthique le plus connu de l'école bouddhiste de Theravada, témoignant ainsi de l'esprit d'ouverture et de la curiosité croissante des traducteurs estoniens.

\section{LA RECHERCHE THÉORIQUE}

Une activité traduisante d'une telle abondance et d'une telle variété, pratiquée par les écrivains les plus illustres et par les plus grands spécialistes d'un pays protéiforme, sanctionnée par une critique constamment en alerte, encouragée et discutée par les instances mêmes du régime, ne pouvait manquer de susciter la polémique et l'éclosion de toute une littérature autour de la traduction. Si, dès le XVIII-XIX ${ }^{\mathrm{e}}$ siècle, des traducteurs comme Trediakovski, Radichtchev, Kapnist, Gneditch et autres Joukovski exprimaient déjà des préoccupations quant à la difficulté et à la manière de traduire, ils le faisaient d'un point de vue essentiellement esthétique ou, si l'on préfère, artistique. Elles procédaient de conceptions limitées à la traduction littéraire et, trop souvent, à la seule traduction poétique, tournant dans bien des cas à des querelles de métrique ou de prosodie. Elles n'étaient pas le fruit d'une réflexion sur le processus de traduction dans sa totalité et n'ont pas engendré de textes théoriques. Et ce n'est pas davantage la scission des traducteurs en deux camps - les partisans d'une traduction aristocratique (c'est-à-dire élégante), d'une part, les défenseurs d'une traduction démocratique, d'autre part - qui réussit à déboucher sur une démarche plus fondamentale. Les traducteurs de l'époque ignoraient jusqu'à l'existence d'une science linguistique et, à plus forte raison, la notion de théorie de la traduction leur était-elle inconnue.

Le premier document à visée théorique ne vit le jour qu'au lendemain de la Révolution. Il s'agit des Principes de la traduction artistique (1919) de Korneï Tchoukovski, qui réunissaient les cours donnés par l'auteur aux traducteurs-stagiaires de $L a$ Littérature universelle. Ce n'était encore qu'une analyse sommaire, celle d'un artiste qui tentait de dégager de sa pratique quelques idées maîtresses basées sur divers facteurs objectifs de la langue, de style, etc., et dont la conclusion demeurait encore bien dans l'optique artistique dominante, puisqu'elle affirmait que pour une traduction «l'essentiel, c'est l'âme». Les écrits sur la traduction publiés pendant la première moitié du siècle révèlent par leur titre même que la traduction littéraire restait le seul objet d'étude et que la traduction continuait à être jugée comme un art: en 1927, Le Problème de la traduction en vers, un article du philologue Andreï Fedorov; en 1930, un livre sur L'Art de traduire de Tchoukovski, qui reprenait ses Principes; en 1930 encore, les Procédés et objectifs de la traduction artistique de Fedorov; en 1941, Un art élevé de Tchoukovski et, la même année, De la traduction littéraire de Fedorov encore. Dans ce dernier ouvrage, Fedorov annonçait déjà une prise de position plus résolument linguistique en déclarant que «la pertinence d'une traduction signifie exactitude extrême dans la restitution du contenu sémantique de l'original et conformité pleinement équivalente au point de vue fonctionnel et stylistique». Fedorov fut aussi le premier à quitter le champ clos de la littérature en faisant paraître sa Théorie et pratique de la traduction de textes scientifiques et techniques allemands (1937-1941) et à s'intéresser aux problèmes de l'enseignement avec ses Questions de théorie et de méthodologie de la traduction dans l'enseignement (1950).

Ce n'est toutefois qu'en 1952, avec un article d'Andreï Reformatski intitulé Les Questions linguistiques de la traduction que les ressources de la linguistique furent mises en cuvre pour aider à l'analyse du processus de traduction. Fedorov, en bon philologue, s'en servit aussitôt pour écrire son Introduction à une théorie de la traduction (1953), qui soulignait la primauté de l'aspect linguistique de la traduction et le caractère indispensable des recherches linguistiques pour élaborer une théorie générale de la traduction. Le 
débat était lancé. Avant 1950, la langue faisait partie d'une idéologie. Au début des années 1930, on avait réédité les écrits de Marx et Engels où il était question de traduction: Comment il ne faut pas traduire Marx (1885) et Remarques sur Carlisle de Engels, correspondance de Marx avec l'éditeur Bracke sur la traduction de La Commune de Paris. Le théoricien N. J. Marr (1864-1934), qui dans la pensée marxiste avait lié l'évolution des langues aux formes de production de la société, subordonnait la langue à la superstructure sociale. En corollaire, la traduction exigeait une mise en forme idéologique; le traducteur devait rechercher non pas l'exactitude linguistique, mais la conformité aux réalités sociales. Staline lui-même s'était déjà prononcé contre Marr en 1940, en soutenant que la langue est un phénomène indépendant de toute base ou superstructure. Mais c'est son article de 1950 sur Le marxisme et les questions de linguistique qui devait marquer de manière décisive l'orientation future. Le livre de Fedorov, très influencé par les idées de Staline, peut être considéré comme une première tentative de poser les règles scientifiques de la traduction. Pour lui, «la traduction est une forme d'activité créatrice au niveau de la langue, un phénomène linguistique à rattacher aux disciplines philologiques».

Ce courant linguistique représenté par Fedorov, Reformatski, Barkoudarov, Retsker et d'autres, fut l'objet de violentes critiques de la part des tenants de la traduction artistique lors du $\mathrm{II}^{\mathrm{e}}$ Congrès des Écrivains soviétiques en 1954 , qui consacra l'existence de deux camps irréductibles. Fedorov, accusé de déviationnisme linguistique, n'en publia pas moins, en 1958, une deuxième édition de son livre en le sous-titrant délibérément Problèmes linguistiques, et les deux tendances continuèrent à s'affronter dans des publications de plus en plus nombreuses. Les répercussions en furent ressenties jusque dans les Républiques: en Ukraine avec L'Art de la traduction (1975) de Maksim Rylski, en Géorgie avec Le Problème de la traduction réaliste (1959) et l'Introduction à la théorie de la traduction artistique (1961) de Ghivi Gatchetchiladze, etc. Si certains esprits comme B. Larine et al. dans Théorie et critique de la traduction (1962), comme B. Ilek dans son article Une théorie scientifique de la traduction littéraire est malgré tout possible (1966) - ont bien essayé de réaliser un compromis en affirmant qu'une théorie de la traduction est impensable sans une liaison organique des méthodes linguistique et littéraire, il est assez significatif que, lorsque fut créé le premier groupement de traducteurs au sein de l'Union des Écrivains, la présidence en fut offerte au littéraire Pavel Antokolski. Les linguistes, de leur côté, fondèrent en 1956, dans le cadre de l'Institut Gorki, à Moscou, la première section de traduction dotée de programmes de formation reposant sur des principes scientifiques. En 1959-1961, c'est un cours de théorie de la traduction qui fut institué à la Faculté de Traduction du Premier Institut pédagogique de Langues étrangères de Moscou. Ce cours, qui visait à lier organiquement les éléments de la théorie linguistique aux techniques de la traduction automatique, a donné naissance au livre de I. Revzin et Iu. Rozentsveig Les Fondements de la traduction traditionnelle et automatique (1964), dans lequel les auteurs montrent que la linguistique structurale et les techniques de l'informatique appliquées à la traduction peuvent contribuer à l'élaboration d'une théorie scientifique de la traduction. C'est encore pour défendre l'option linguistique que Ia. Retsker fit paraître en 1974 sa Théorie et pratique de la traduction.

Les possibilités d'une traduction automatisée avaient d'ailleurs éveillé très tôt l'intérêt des savants soviétiques, puisque déjà en 1933 des suggestions avaient été faites par Smirnov-Troïanski et Arbouni. Mais on ne disposait pas alors des ressources des grands ordinateurs électroniques. Il fallut attendre les années 1955-1956 pour voir D. Panov opérer sur une machine à traduire d'une capacité de 1100 mots, issue des recherches menées à l'Institut de mathématiques Steklov et à l'Institut de Mécanique de Précision et de Technique du Calcul à Moscou. En 1958, il publiait son livre sur $L a$ Traduction automatique et, bientôt, suivirent une multitude de publications sur le sujet. 
La traduction électronique, en effet, avait obligé les chercheurs à étudier divers problèmes soulevés par les rapports entre la langue et la machine (adaptation des langages de programmation à des fins proprement linguistiques, recherche de modèles mathématiques de description formelle des langues, etc.). Ces études ont indiscutablement contribué à une meilleure connaissance des mécanismes de la traduction, mais pas plus qu'en Occident elles n'ont pu répondre à l'objectif premier qui les avait motivées: résoudre le problème de l'abondance de la matière à traduire dans un État multinational. Depuis le lendemain de la Deuxième Guerre mondiale, l'U.R.S.S. occupe la première place parmi les pays grands traducteurs du monde. De 1951 à 1956, pour ne considérer que les livres publiés sur son territoire, la part prise par les traductions représentait $78 \%$ et le nombre de langues traduites s'élevait à 110 , dont 70 parlées à l'intérieur des frontières. Dix ans plus tard, ces chiffres étaient encore respectivement de 32\% (2397 traductions sur un total de 7648 publications) et de 85 , dont 42 langues nationales. À l'échelle mondiale, si l'on s'en réfère aux chiffres de l'Index Translationum (UNESCO), l'U.R.S.S. intervint en 1972 pour $11,5 \%$ dans le total des traductions publiées (4463 sur 39143). Selon ces mêmes sources, elle se classe première également pour la traduction des ouvrages scientifiques, en particulier dans la discipline des sciences exactes et appliquées. Actuellement, 1'U.R.S.S. compte plusieurs milliers de traducteurs - écrivains, philologues, diplômés des écoles de traduction - dont environ un tiers seulement traduisent des langues extérieures. Leur activité embrasse tous les domaines, et le besoin de recenser les résultats de cette entreprise gigantesque se manifeste dans des publications comme le Catalogue de Traductions de la Littérature scientifique et technique étrangère (1957- ) édité par l'Institut de l'Information scientifique et technique à Moscou, le Catalogue de Traductions (1959-) compilé par la Bibliothèque scientifique et technique de l'État à Moscou, les Traductions scientifiques et techniques (1971- ) éditées sous les auspices du Comecon, et bien d'autres.

\section{BIBLIOGRAPHIE}

\section{OUVRAGES}

ADONZ, N. (1946) : Histoire d'Arménie, Paris.

AUGÉ, P. et al. (1933) : Larousse du XX $X^{e}$ siècle, 6 vol., Larousse, Paris.

BRAUNECK, M. (1981) (éd.): Weltliteratur im 20, Jahrhundert, 5 vol., Rowohlt, Reinbeck / Hamburg.

GILLON, E. et al. (1964) : Grand Larousse Encyclopédique, 10 vol., Larousse, Paris.

HARGREAVES-MAWDSLEY, W. N. (1968) : Dictionary of European Writers, F. M. Dent \& Sons, London. HOETINCK, H. R. et al. (1960) : Algemene Winkler Prins Encyclopedie, 10 vol. + suppl., Elsevier, Amsterdam. HOFMANN, M. (1946) : Histoire de la littérature russe, Paris.

KRYWALSKI, D. (1979) (éd.) : Lexikon der Weltiteratur, Droemer Knaur, Münche

LAFFONT-BOMPIANI (1980) : Dictionnaire des auteurs, 4 vol., R. Laffont, Paris.

LO GATTO, E. (1965) (trad. M. Cabrini) : Histoire de la littérature russe des origines à nos jours, Desclée-De Brouwer, Bruges.

MANVELICHVILI, A. (1951) : Histoire de Géorgie, Nouvelles Éditions de la Toison d'Or, Paris.

TER-PETROSSIAN, L. (1984): La littérature arménienne ancienne de traduction, Erevan.

\section{ARTICLES}

AKOPIAN, A. (1982) : «Goethe en Arménie», Babel, 28-4

BANG, P. (1955) : «Das Problem der Übersetzung in sowjetischer Sicht», Sprachforum, 1-2.

BRAGUINSKI, I. \& N. KHALFIN (1962) : «Traductions des littératures des peuples orientaux en U.R.S.S.», Babel, 8-3.

CARY, E. (1957) : «Théories soviétiques de la traduction», Babel, 3-4.

CARY, E. (1964) : «G.R. Gatchétchiladzé», Babel, 10-1.

FEDOROV, A. (1978) (trad. T. Mrsic) : «Histoire et théorie de la traduction en U.R.S.S.», Babel, $24 / 3-4$

GACHECHILADZE, G. (1964) : «Literary Translation in Georgia», Babel, 10-3.

GACHECHILADZE, G. (1965): «Ivane Machabeli, The Great Georgian Translator of Shakespeare», Babel, $11-3$. 
GANIEV, V. (1979) : «Le Conseil de la Traduction littéraire de l'Union de Écrivains de l'U.R.S.S.», Babel, 25-1. GREBENSCHIKOW, V. (1967) : «Traductions, théories et traducteurs en U.R.S.S.», Meta, 12-1.

KALACHNIKOVA, E. (1966) : «Translation in the U.S.S.R.», Babel, 12-1.

KGRALACHVILI, R. (1982): «Goethe en Géorgie», Babel, 28-4.

KOPTILOV, V. (1979) : «La traduction en Ukraine», Babel, 25-1.

MAHÉ, J.-P. (1984) : «Origine et formation de la langue arménienne», Armonia (Paris).

MEYNIEUX, A. (1957) : «Les traducteurs en Russie avant Pouchkine», Babel, 3-2.

MEYNIEUX, A. (1961) : «L'Antiquité gréco-latine en Russie, de Pierre le Grand à l'Âge d'or», Babel, 7-3.

MEYNIEUX, A. (1961) : «Pouchkine et sa traduction en français», Babel, 7-3.

MKRTCHYAN, L. (1979) : «To know wisdom and instruction (Armenia)», Babel, 25-1.

RADO, G. (1968): «A Great Ukrainian Translator - Pavlo Hrabovski», Babel, 14-1.

SAMNA, O. (1979) : «L'Cuvre de traduction en Estonie», Babel, $25-1$.

SAMNA, O. (1982): «Goethe en Estonie», Babel, 28-4.

SCHWARZ, H. (1981) : «Sowjetunion heute», Babel, $27-4$.

VISOCKAS, V. (1982) : «Goethe en Lituanie», Babel, 28-4. 